Rev. Hist., $\mathrm{N}^{\circ} 26$, vol. 2, Julio-Diciembre 2019: 183 - 217

ISSN 0717-8832

\title{
Reforma agraria en Tequila (Jalisco, México), 1915-1980*
}

\author{
Agricultral reform in Tequila (Jalisco, Mexico) 1915-1980
}

Gladys Lizama Silva**

\section{RESUMEN}

Los objetivos centrales del trabajo son tres: retomar la historiografía jalisciense sobre la reforma agraria en el Estado; la discusión del uso del concepto campesino en este proceso, y narrar cómo y cuándo se realizó la de la ciudad de Tequila, a partir de documentación original, entre 1915 y 1980, poco o nada estudiada y depositada en el Archivo de Asuntos Agrarios del estado de Jalisco. La hipótesis central se afirma en que forma parte de un mismo proceso llevado a cabo en distintos espacios de Jalisco, en esa etapa, sin embargo, tiene la particularidad que las tierras a repartir eran -son- productoras del agave tequilana weber materia prima para la elaboración del tequila, bebida alcohólica industrializada desde la era porfiriana. Argumento que sirvió a los productores para desestimar el reparto porque esta industria era próspera y la consecuencia sería la afectación a la región. Los hechos les dieron la razón, no obstante, no es ni con mucho la única explicación para el deterioro y decrecimiento de la producción de tequila en esa década y en las que siguen, situación que trataré de demostrar en el desarrollo del trabajo. Para ilustrar el resultado de la aplicación de la reforma agraria en Tequila proporciono al final un mapa con la división ejidal en la década de los años treinta del siglo pasado.

Palabras claves: reforma agraria, historiografía, Tequila, formación ejidal

\section{SUMMARY}

Three are the main objectives of this research: recapture the historiography on the agricultural reform of Jalisco, the discussion of the use of the concept peasant in this process, and recount how and when this reform took place in the town of Tequila, based in original documentation for the period between 1915 and 1980, all of which is deposited in the Archive of Agrarian Matters of the State of Jalisco and is very little known or scarcely studied. The main hypothesis here is that this reform is part of the same process that affected other areas of the State of Jalisco. However, in the particular case of Tequila, the land to be divided was -and still is- dedicated to the production of agave tequilana weber, which is the raw material to produce the liquor known as tequila, industrialized since the Porfirian era. This argument served the land owners to reject the division of the land because this industry was very prosperous and otherwise the region would have been seriously affected, something that reality demonstrated that they

\footnotetext{
*Este artículo es uno de los resultados del proyecto: "Estudio de las regiones de Jalisco, México". Agradezco la colaboración de Fernanda Pizano, alumna de Licenciatura en Historia, la transcripción de los diferentes documentos que sirven de fuentes en este documento.

** Doctora en Historia, Académica Universidad de Guadalajara, México. Email: gladyslisil@gmail.com
} 
were right. But this is not the only explanation for the deterioration and decay of this industry at that time and the decades that followed, something I shall try to prove in this work.

To illustrate the effects of the agricultural reform in Tequila, a map will be presented, in the final part of the study, with the division of the communal land (ejido) during the 30 s of last century.

Key words: Agricultural Reform, Historiography, Tequila, Formation of the Ejido

Recibido: junio 2019

Aceptado: diciembre 2019

\section{Introducción}

El agrarismo fue el basamento político del reparto agrario. Como ideario no era homogéneo, osciló entre corrientes radicales como la de Adalberto Tejeda en Veracruz y moderadas como la representada por Lázaro Cárdenas. Romana Falcón afirma al respecto "el término de agraristas cobijaba a personajes muy disímiles." ${ }^{1}$ Las primeras organizaciones pilares del agrarismo surgen en los años 20 y buscaban una transformación de la estructura de la gran propiedad en México. Por un lado, repartir las tierras entre los que no las tuvieran, utilizando la figura jurídica ejido, entendido como propiedad del Estado entregada a los ejidatarios de manera colectiva para que sirviera de sustento a las familias del campo. La misma autora señala que "desde el principio del movimiento pueden encontrarse profundas divergencias sobre los objetivos y métodos de la revolución en relación al México rural. Mientras algunas corrientes se pronunciaron por la entrega de tierras a los pueblos a costa de la grande e incluso mediana propiedad privada, otras como "el grupo de Sonora" no tardó en poner en claro sus preferencias por formar un país de medianos propietarios prósperos e independientes." ${ }^{2}$ En suma, los agraristas pensaban que los problemas económicos rurales de México solo se arreglarían con el desmantelamiento de la hacienda para formar ejidos. Los más radicales conformaron milicias armadas para defender las tierras ganadas con la reforma.

Desde otro punto de vista Jean Meyer asevera que el agrarismo fue un instrumento de los gobiernos postrevolucionarios que:

"explica el encarnizamiento con que los cristeros habrían de perseguir a los agraristas, condenados a servir militarmente al gobierno, despreciados y sacrificados por un ejército que los empleaba como carne de cañón, cubiertos de vergüenza y detestados por los campesinos cristeros que los acusaban de haber vendido su alma por un pedazo de tierra;

\footnotetext{
${ }^{1}$ Falcón, R. 1978. “El surgimiento del agrarismo cardenista: una revisión de las tesis populistas”, Historia Mexicana, Vol. 27, $\mathrm{N}^{\circ} 3$, p. 350.

2 Ibid, p. 348.
} 
[luego enfatiza que] el gobierno utilizó siempre a los agraristas con fines de control político, de policía rural y de acción militar. Este proceso culminó en enero de 1929, cuando las milicias agraristas fueron colocadas bajo autoridad militar y organizadas como 'Primera Reserva del Ejército Nacional'”3.

Respecto de la legislación agraria que marcó el proceso de reparto de tierras habría que señalar que en 1916 se crea la Comisión Nacional Agraria, después que ya estaban instituidas y trabajando 27 comisiones agrarias locales en el país. Los integrantes de la Comisión Nacional Agraria eran nueve personas nombradas por autoridades federales y presidida por el secretario de fomento; cada comisión local agraria se componía por cinco integrantes y tres personas constituían los comités particulares ejecutivos, los que formaron ambos tipos de instituciones fueron designados por los gobernadores. ${ }^{4}$ Fue así como "se instituyeron [las] autoridades agrarias: [a saber] el Presidente de la República, la Comisión Nacional Agraria, los gobernadores de los estados, las comisiones locales agrarias, las delegaciones de la Comisión Nacional Agraria en los estados y los comités particulares ejecutivos." ${ }^{5}$

El modelo del procedimiento para la repartición de tierras ha sido descrito por muchos autores pero puede sintetizarse así: 1) presentación de la solicitud de restitución de tierras por los integrantes del pueblo, 2) esta era recibida por el poder ejecutivo del Estado, vale decir, el gobernador; 3 ) la Comisión Local Agraria se encargaba de hacer el estudio de la viabilidad de la solicitud; 4) el Comité Particular Ejecutivo debía ocuparse del deslinde de las tierras; 5) la resolución de este comité se enviaba al gobernador del Estado quien podía otorgar la posesión provisional de las tierras expropiadas y repartidas; 6) la Comisión Agraria Local elaboraba un informe de las resolución sobre las tierras a repartir; 7) la Comisión Nacional Agraria era la encargada de aprobar, rectificar o modificar la resolución provisional de cada Estado; 8) la resolución definitiva de restitución o dotación de tierras era otorgada solo por el presidente de la república. ${ }^{6}$

Laura Gómez Santana afirma que la descripción anterior corresponde a un modelo ideal, que distó de ser el camino real jalisciense pues:

"existieron elementos formales que interfirieron en el curso de las solicitudes: [como] los vacíos legales, la poca habilidad de las autoridades agrarias y la falta de personal. Los

\footnotetext{
${ }^{3}$ Meyer, J. 1995. La Cristiada. Los cristeros, Vol III, México, Siglo XXI, pp. 77 y 85.

${ }^{4}$ Gómez Santana, L., 2009, “Identidades locales y la conformación del estado mexicano, 1915-1924: comunidades, indígenas y pobres ante el reparto agrario en Jalisco central", Tesis de doctorado, Universidad de Guadalajara, Guadalajara.

5 Gómez Silva Cano, J. 2017, "Evolución del marco jurídico agrario", en El derecho agrario mexicano y la Constitución de 1917, INEHRM, p. 175.

6 Gómez Santana, L., 2009, “Identidades locales y..., p. 61.
} 
pueblos tuvieron que enfrentar un sinnúmero de retrasos e inversión de recursos, principalmente en la búsqueda de documentos y pruebas, largas esperas de los ingenieros, de los dictámenes y de las resoluciones gubernamentales. A su vez, de manera informal, las solicitudes de tierras se vieron obstaculizadas por la fuerte resistencia de los terratenientes, las autoridades locales y el clero al reparto de tierras. Asimismo, los conflictos entre pueblos vecinos también prolongaron los procedimientos agrarios."

En 1915, la Comisión Local Agraria de Jalisco estaba constituida por un presidente, tres vocales, cinco escribientes y un mozo; le fueron asignados tres ingenieros encargados de recabar la información de las solicitudes de restitución o dotación y elaborar los planos respectivos. Para la elaboración de los planos se emplearon un dibujante y un calculista. En 1921 se contrató una mecanógrafa y un visitador de ejidos, quien como su nombre lo indica era una especie de inspector que observaba en terreno los tipos de cultivo, los productos obtenidos, las utilidades si las había y las condiciones de vida de los indígenas y habitantes de las tierras a reformar. ${ }^{8}$ Este pequeño aparato burocrático no fue perenne, experimentó cambios, es así que en el gobierno de Antonio Valadez se eliminó personal y dejaron solamente a los topógrafos o ingenieros titulados.

Casi la mayor parte de los propietarios afectados recurrieron a las instancias legales tradicionales a fin de resguardar sus haciendas; fue así que hicieron uso del amparo y el juicio civil contra el reparto de tierras, al cabo que las instancias del poder judicial siempre actuaron favoreciendo a la gran propiedad, fueron contrarios al reparto agrario y antiagraristas por antonomasia. Por ello el aparato estatal posrevolucionario separó el proceso de reparto agrario situándolo en el poder ejecutivo y por la vía administrativa, como bien lo narra Helga Baitennann. ${ }^{9}$

En 1931 se hizo una enmienda a la ley del 6 de enero de 1915 que impidió que los propietarios afectados por el reparto agrario tuvieran acceso a amparos, situación que negó a los terratenientes el derecho de recurrir a los tribunales de justicia. Solo podían en adelante reclamar el pago de una indemnización. ${ }^{10}$

\section{La ciudad}

Tequila se encuentra en una zona ligeramente plana y al pie del cerro de Tequila; el clima es templado, el régimen de lluvias irregular, empezando en junio para terminar a fines de

\footnotetext{
7 Ibid, p. 59.

${ }^{8}$ Ibidem, p. 60.

9 Baitenmann, H. 2017, “Ejerciendo la justicia fuera de los tribunales: de las reivindicaciones decimonónicas a las restituciones de la reforma agraria," en revista Historia Mexicana, LXVI: 4.

${ }^{10}$ Barreto Zamudio, C. 2019, "La persistencia de los hacendados azucareros del estado de Morelos frente al reparto agrario, 1920-1930. Un estudio de caso”, en LETRAS HISTÓRICAS, Universidad de Guadalajara, 91-113.
} 
septiembre o principios de octubre; la vegetación espontánea de la región es cerril. ${ }^{11}$ Está a una distancia aproximada de 1.000 m de la caja del Río Grande o de Santiago, y a 75 km Guadalajara; las superficies de riego son exiguas y por consiguiente solo un reducido número de vecinos se beneficia

En 1910 tenía 3.942 habitantes de los cuales 1.816 eran hombres y 2.126 mujeres. ${ }^{12}$ Los principales cultivos eran el agave y el maíz, las tierras tenían un rendimiento de 80x1 y una cosecha al año en este último. En 1936 los rendimientos que se obtenían del maíz eran menores, solo $70 \times 1$ y se agregó el cacahuate que llegaba a $200 \times 10$. En 1915 el jornal promedio era de \$1 diario; en 1936 continuaba siendo igual. ${ }^{13}$ La disponibilidad de agua para consumo humano y de las fábricas provenía del arroyo Atiscoa; la dotación era de 60 litros aproximadamente -sin especificar si por cada casa o familia- y por obtenerla se pagaba una renta al municipio.

En 1915 había seis fábricas de tequila de los siguientes propietarios: Ana González Rubio vda. de Cuervo, Eladio Sauza, Cipriano Rosales, Miguel Flores, Luis Plascencia, Miguel Rosales Armas, Luis Sauza y la de Enrique Aguirre que está en La Barranca cerca del rancho La Toma. ${ }^{14}$ En esa misma fecha la producción había descendido en casi 50\%, situación que se tradujo a su vez en una baja en la recaudación de impuestos al alcohol "en un 60\% entre 1915 y 1929" en el municipio de Tequila. ${ }^{15}$

En 1936, debido a la reducción del cultivo del maguey para la elaboración de tequila, las fuentes de trabajo escasearon, las fábricas ocupaban un reducido número de trabajadores, por lo que los vecinos únicamente podían dedicarse a la explotación de la tierra y de los bosques. ${ }^{16}$ En 1921 la mayor parte de los trabajadores se empleaba en esta actividad y sus salarios eran los siguientes:

\footnotetext{
${ }^{11}$ Archivo de Asuntos Agrarios del estado de Jalisco (en adelante AAAEJ), Comisión Local Agraria (en adelante CLA), Exp. 34, Resumen final, p. 3.

${ }^{12}$ AAAEJ, CLA, Exp. 34, p. 71.

${ }^{13}$ AAAEJ, CLA, Exp. 34, p. 71 y Expediente 937, 1a Ampliación, p. 2.

${ }^{14}$ AAAEJ, CLA, Exp. 34, p. 60.

${ }^{15}$ Luna Zamora, R., 1999, La historia del tequila, de sus regiones y sus hombres, México, CONACULTA, p. 110. Con relación al impuesto sobre el tequila el autor no aclara si este era sobre la venta o la producción por litro de la bebida alcohólica. A nivel federal, según Graciela Márquez en "¿Modernización fiscal? Impuestos sobre bebidas alcohólicas, 1884-1930," en Cruda realidad. Producción, consumo y fiscalidad de las bebidas alcohólicas en México y América Latina, siglo XVII-XX, Ernest Sánchez Santiró (Coord.) México, Instituto Mora, 2007, p. 200, la tasa de los impuestos de timbre aplicados a las ventas de alcoholes destilados nacionales por los gobiernos revolucionarios aumentaron considerablemente la recaudación entre 1912 y 1922, al respecto cito: "El 1 de septiembre de 1918, Venustiano Carranza reconocía que los impuestos sobre alcoholes tenían un rendimiento favorable gracias al aumento de cuotas [...] Mientras que para 1912-1913 [fue de] 2.61\% [...], para 1922 el impuesto sobre alcoholes aumentó a 5.65\% del ingreso público total de 1922."

${ }^{16}$ AAAEJ, CLA, Expediente 937, 1a Ampliación, p. 2v.
} 
Tabla 1. Salarios de los jornaleros en fábricas de tequila, 1921

\begin{tabular}{|c|c|}
\hline Tipo de trabajo & Monto diario en pesos de la época \\
\hline Labor/Jornal & 1 \\
\hline Limpia de mezcal por mil unidades & 4 a 7 \\
\hline Jima por cien cargas & 5 a 7 \\
\hline $\begin{array}{c}\text { Peones en alambiques, tainas, cargueros, } \\
\text { motoristas }\end{array}$ & 1 \\
\hline
\end{tabular}

Fuente: Elaboración propia, AAAEJ, CLA, Exp. 34, pp. 60 y Resumen final, p. 2v.

El trabajo se organizaba anualmente de la siguiente forma: "cuando se acerca el tiempo de la preparación de las tierras para la siembra del maíz y hasta su cosecha, son retirados los trabajadores de la plantación, limpia y jima del maguey para dedicarlos al trabajo de la labor y pasada esta vuelve a las fábricas." ${ }^{17}$

\section{Historiografía de la reforma agraria en Jalisco ${ }^{18}$}

El trabajo de Robert J. Knowlton ${ }^{19}$ sobre la individualización de la propiedad corporativa civil en Jalisco durante el siglo XIX, es un clásico ineludible que aclara varios aspectos de la privatización de las tierras propiedad del ayuntamiento de Guadalajara, de la clasificación de los tipos de propiedad corporativa, de la legislación privatizadora liberal promulgada en Jalisco a lo largo del siglo XIX y del incumplimiento de la misma tanto por los ayuntamientos como por las comunidades indígenas jaliscienses y, por último, de la repartición de tierras entre los indígenas del pueblo de Santa María, el cual formó parte del cantón de Guadalajara. Para efectos de este trabajo es de primera importancia lo que Knowlton define sobre las clasificaciones de los tipos de propiedad y también la secuencia de leyes que ordenaron repartir las tierras comunales, a saber: decreto 2 de la ley de 1825, decreto 151 de la de 1828, decreto 121 de la ley de 1849, la ley Lerdo de 1856 que ordenaba la venta de la propiedad corporativa eclesiástica y civil, destacando que en esta última se incluyó la que tenían en común, valga la redundancia, la comunidades indígenas. Llama mucho la atención el relato sobre la repartición de las tierras comunales del pueblo Santa María aledaño a Guadalajara, efectuada a partir de 1881, porque coincide con lo descrito en el Expediente $\mathrm{N}^{\circ} 34$ de Tequila, en el cual la narrativa cuenta que la situación de la propiedad de las tierras indígenas en dicha ciudad se mantuvo más o menos en

\footnotetext{
${ }^{17}$ AAAEJ, CLA, Exp. 34, p. 60.

${ }^{18}$ He omitido referirme a la historiografía clásica nacional exclusivamente por falta de espacio, ver al respecto: Arturo Warman, "La reforma agraria mexicana: una visión de largo plazo". Andrés Molina Enríquez, varias ediciones desde 1909, Los grandes problemas nacionales y La propiedad agraria en México. María Teresa Jarquín, 1990, Origen y evolución de la hacienda en México: siglos XVI al XX. El Colegio Mexiquense A.C., Universidad Iberoamericana, Instituto Nacional de Antropología e Historia http://www.fao.org/3/j0415t/j0415t09.htm

19 Knowlton, R. 1978, "La individualización de la propiedad corporativa civil en el siglo XIX - Notas sobre Jalisco", Historia Mexicana, Vol. 28, Nº 1, pp. 24-61.
} 
paz hasta 1882; a partir de ese año los indígenas fueron obligados a dividir su propiedad y, a manera de hipótesis se puede decir que al parcelarlas muchos de ellos luego las vendieron o las perdieron por deudas contraídas, o los grandes propietarios simple y llanamente transgredieron límites despojando con ello de tierras a los indígenas y con la anuencia de las autoridades locales. Tomando como punto de referencia la historia que cuenta Knowlton, sobre el pueblo de Santa María, se puede concluir que es a comienzos de la década de 1880 que comienza en Tequila la ola privatizadora de la instancia municipal por la hipotética presión de los grandes propietarios para expandir sus campos de cultivo a fin de dedicarlos a la plantación de agaves.

Rogelio Luna Zamora, ${ }^{20}$ dedica varias páginas de su libro a narrar los rasgos y perfiles que tuvo la reforma agraria en los municipios de Tequila, Amatitán, El Arenal y Magdalena. Llama la atención que la mirada de este autor ubica los primeros repartos de tierras en 1927, "con la dotación a ejidatarios en los municipios de Tequila, Magdalena y Arenal, pero fue en los años 30 bajo el régimen del general Cárdenas, cuando se efectuó el reparto de la casi totalidad de la superficie afectable de la región." ${ }^{21}$ Afirmación que para el de Tequila no es del todo cierta, pues según el expediente $\mathrm{N}^{\circ} 34$ se dotó de tierras a los solicitantes de la comunidad indígena de la ciudad hasta 1929, después de largos años de lucha que comenzaron en 1915, primero exigiendo la restitución y cuando este trámite se agotó por indemostrable se procedió a pedir la dotación.

Con base en el Diario Oficial de la Federación, Luna presenta los datos de la expropiación de tierras en Tequila entre 1930 y 1941, años que no incluye el Expediente $\mathrm{N}^{\circ} 34$. El Cuadro 21, titulado "Núcleos, superficie y tipo de tierras y predios afectados con el reparto agrario. Municipio de Tequila," ${ }^{22}$ comprendido en su texto, ofrece algunas variables cuantificadas, a saber: año de la afectación, núcleo agrario objeto de afectación, superficie en dotación, número de ejidatarios beneficiados, tipo de tierras afectadas o dotadas (temporal, riego y agostadero), superficie de la hacienda afectada, nombre de la misma y los nombres de los propietarios de los predios. El número de hectáreas entregadas en dotación entre 1930 y 1941 fue de $8.494 \mathrm{~h}$ a 826 ejidatarios; ${ }^{23}$ la cifra total de hectáreas por afectar entre los mismos años fue de 42.619 .

\footnotetext{
${ }^{20}$ Luna Zamora, R. 1999, La historia del tequila..., p. 127-153. Las fuentes documentales de estas páginas son el Diario Oficial de la Federación de 1927 a 1942, el Directorio General del estado de Jalisco, 1930-1931 y de 1937-1938 y el Censo Agrícola Ganadero de 1940.

${ }^{21}$ Ibid, p. 133.

22 Ibidem, pp. 134-139.

${ }^{23}$ Luna Zamora no utiliza las categorías: campesino, indígena, jornalero, tampoco el calificativo "legalmente capacitados para solicitar y obtener tierras por concepto de dotación o restitución", expresado en el AAAEJ, CLA, Exp. 34, p. 8. O "capacitados para obtener ejidos", AAAEJ, CLA, Exp. 34, p. 12.
} 
O sea, para tener una idea más cercana hay que decir que solo se afectó el $20 \%$ de las tierras de los propietarios.

Toda la superficie otorgada en dotación fue tierra de agostadero y temporal, las sumas de los datos entregados por Rogelio Luna son: 6.961 y 3.961 hectáreas respectivamente. Verán que la suma de estas dos últimas cifras no coincide con la del total de hectáreas entregadas en dotación, por lo tanto, no es posible obtener los porcentajes reales de cada una. Los propietarios a los cuales se les aplicó la reforma de sus tierras fueron: Ana González viuda de Cuervo, Francisco y Abel García Martínez, testamentaría de Miguel Rosales Armas, Sucesión Cenobio Sauza, Melquiades Rivera, Luis Ávila, Luis J. Sauza, Eladio Sauza, Olivia Ruiz, Cía. Agrícola Occidental, Oscar R. Gallardo, Aurelio López, Sucesión Enrique Aguirre, Guadalupe Gallardo, María de Jesús López y Rosales, y Rafael Ruiz Díaz. Obviamente hubo diferencias notables entre la cantidad de hectáreas que se expropiaron a cada uno de estos terratenientes.

El segundo libro de Rogelio Luna Zamora, ${ }^{24}$ dedica solo cinco de sus páginas a la reforma agraria en las regiones tequileras de Jalisco. Es entendible porque este tema ya lo había desarrollado en el primer texto. ¿Cuál es su narrativa al respecto? Ratifica lo dicho en La historia del tequila..., es decir, que la reforma agraria afectó considerablemente la producción tanto de agave como de tequila. Este decremento significó una disminución en la recaudación de impuestos sobre el tequila de 60\% entre 1915 y 1929. Una reducción del 50\% del número de destilerías en el municipio de Tequila, más o menos entre las mismas fechas (de 16 a 8). Cito:

“En relación a los volúmenes de destilación, de 1901 a 1935, la caída fue del 90\%, al alcanzar la destilación cerca de dos millones de litros en 1930, y de apenas un millón en 1935, frente a los casi diez millones de 1901. [....] Por otra parte, los aproximadamente 70 millones de agaves existentes en 1901, habían disminuido para 1910 a 20 millones [1912-1913] y, dramáticamente alcanzado apenas los 4 millones de plantas en 1940, en una extensión de 2.603 hectáreas." 25

Otro de los efectos negativos, realzado por Luna respecto al tequila, refiere que los ejidatarios receptores de tierras con plantaciones de agave fueron descuidadas $y$ eventualmente abandonadas, además, con frecuencia aprovechaban las piñas en condiciones de producción para realizar el proceso de producción clandestino de tequila. Otro rasgo que hace notar el autor es que los antiguos hacendados y productores de tequila conservaron la maquinaria para el proceso productivo completo del tequila, pero un número limitado de hectáreas de sembradío de agave (300 hectáreas como máximo), situación que también

\footnotetext{
${ }^{24}$ Luna Zamora, R. 2015, La Construcción cultural y económica del tequila, Guadalajara, Universidad de Guadalajara. ${ }^{25}$ Luna Zamora, R. 2015, La Construcción.., pp. 111-112.
} 
contribuyó, y mucho, al decrecimiento de la industria tequilera y a que estos movieran sus actividades principalmente a la ciudad de Guadalajara.

Laura G. Gómez Santana estudió 46 pueblos “beneficiados con tierras durante el periodo de 1915 a 1924 en Jalisco, [...] 43 de ellos se localizaban en la zona centro del estado," 26 entre los cuales se encontraba Tequila. El objetivo central es dar cuenta de la nueva construcción del concepto indígena que surge durante la revolución de 1910 y los años que siguieron, tanto en la tradición oral como en la historiografía de la época. Responde preguntas como ¿quién era indígena y quién no? Definición central, -podría catalogarse como estratégica-, en esos tiempos, para ser beneficiario del reparto de tierras a partir de la promulgación de la ley del 6 de enero de 1915, que no estableció en su contenido la condición de ser indígena para obtener tierras, no obstante, dice la autora "hubo comunidades que construyeron su legitimidad sobre la posesión de la tierra a partir de este precepto."27 Una particularidad de la zona centro de Jalisco con relación a su población es que el proceso de mestizaje provocó que los pueblos indígenas perdieran su lengua y costumbres ancestrales, de tal forma que la identidad en esta región se forjó con base en el lugar geográfico y la comunidad humana que lo habitaba. Esta transformación se ahondó aún más con la legislación liberal tendiente a considerar a todos los habitantes como iguales y a quitarle a las corporaciones civiles de carácter étnico su categorización como pueblo y transformarlos en municipios o instancias dependientes de estas instituciones, llegando incluso a ser excomunidades indígenas. Recuerda la autora que es en la segunda mitad del siglo XIX cuando se sientan las bases de una nueva categoría de indígena en el ámbito de la antropología e historia de la época. Se enaltecieron y encumbraron las antiguas culturas azteca y maya, se censuró y tildó al indígena vivo como flojo e incompetente y se creó en el imaginario decimonónico al mestizo como el ideal de hombre. Al sobrevenir la revolución de 1910 y la subsiguiente transformación de la estructura de la propiedad de la tierra, surge de nuevo quien tiene derecho a recuperar las tierras despojadas a través de siglos, ¿quiénes eran estos?: pues los indígenas. Por lo tanto, estas comunidades con una tradición de habitación común de un lugar ancestral recurren a la antigua legislación virreinal de los títulos de propiedad de las tierras para exigir la restitución de las mismas y para ello fue necesaria la recuperación de la categoría indígena. En el caso de Tequila la comunidad que luchó por la restitución se autodenominó como el indigenado, al respecto cito:

"existió en los tiempos del Gobierno Virreynal (sic) formal congregación mancomunada de los aborígenes o primitivos habitantes que, protegidos por leyes y cuidados especiales, gozaron de personalidad en conjunto, formando el indigenado y mereciendo el honor de

\footnotetext{
${ }^{26}$ Gómez Santana, L., 2009, "Ser indígena en la reforma agraria. Jalisco, México, 1915-1924", revista Sociedad Hoy $N^{\circ} 17$, Universidad de Concepción, p. 104.

${ }^{27}$ Ibid.
} 
constituir entidad jurídica con todas las prerrogativas y privilegios necesarios para su objeto." 28

Muchas páginas adelante encontramos nuevamente esta categorización de indigenado a propósito de la destitución de dirigentes corruptos y no indígenas de Tequila, el documento afirma que:

"dada la designación anterior, la cual hasta hoy no se había efectuado con pleno acuerdo de este indigenado, quedan por lo mismo desconocidos quienes de manera ilegal han llevado esas representaciones y son los señores Casimiro Pazos, y Ernesto García el primero como Presidente o representante, cargo que tiene renunciado y cuya renuncia se le acepta de plano y el segundo, como Tesorero, desconociéndolos aún en su calidad de indígenas como hasta hoy se han hecho pasar sin ser oriundos de ese pueblo como es notorio." ${ }^{29}$

La tesis doctoral de Laura G. Gómez Santana ${ }^{30}$ es simultánea en aparecer al artículo comentado líneas arriba, por lo tanto, hay temáticas que están contenidas en ambos trabajos, razón más que suficiente para no repetirlas. Los objetivos de la tesis doctoral son más amplios y se sintetizan así: 1) mostrar que la categoría de campesino es una construcción económica, social y política producto de la revolución y del reparto de tierras después que esta terminó; categoría que acabó por instituirse como tal tanto por intelectuales de la época, como por la historiografía y antropología, prioritariamente marxista. Simple y llanamente esta no existía al momento de iniciarse el reparto agrario. ${ }^{31}$ 2) Narrar con base en documentación de primera mano cómo se habían construido las identidades locales de los vecinos que habitaron los pueblos, las comunidades indígenas principalmente rurales y los pobres, que solicitaron tierras; en concreto de 46 pueblos de la región central de Jalisco. 3) Reconstruir la legislación agraria que orientó, rigió y se impuso para el reparto de tierras desde 1915 hasta 1924. A diferencia del trabajo de Helga Baitenmann, Laura G. Gómez Santana no hace la diferencia en la transformación de la misma desde el siglo XIX al XX entre los ámbitos judicial y administrativo,

\footnotetext{
${ }^{28}$ AAAEJ, CLA, Exp. 34, p. 1.

${ }^{29}$ AAAEJ, CLA, Exp. 34, p. 54.

${ }^{30}$ Gómez Santana, L., 2009, “Identidades locales y la conformación del estado mexicano, 1915-1924: comunidades, indígenas y pobres ante el reparto agrario en Jalisco central", Tesis Doctoral, Universidad de Guadalajara, Guadalajara.

31 Kourí, E. 2017, "Sobre la propiedad comunal de los pueblos. De la Reforma a la Revolución”, Historia Mexicana, LXVI: 4, p. 1947, asevera que ha habido una "ceguera [en el uso del] término que habitualmente se ha utilizado y se sigue utilizando para describir y categorizar a los habitantes de [los] pueblos: campesinos. Esta es una palabra que prácticamente no fue utilizada en México antes del siglo XX: por lo general no habían campesinos ni en las leyes ni en los documentos oficiales o en la prensa antes de la Revolución; tampoco en los escritos provenientes del campo mismo, en los cuales se nombran vecinos, hijos del pueblo, labradores, naturales, indios, etc., pero nunca campesinos."
} 
que es crucial para que el Ejecutivo pudiera llevar a cabo ese cambio estructural; el poder judicial durante el siglo XIX siempre fue renuente en legislar en pleitos de tierras a favor de los despojados y, obvio, casi siempre daba la razón a grandes y medianos propietarios que con frecuencia eran despojadores de tierras ilegalmente.

Luego enumera y comenta los decretos leyes en dos periodos, a saber, 1915-1924, donde se promulga el decreto de 6 de enero de 1915, base legal de las primeras acciones de la comunidad de Tequila y todas las restantes para solicitar la restitución de tierras, proceso descrito más adelante. Lo medular de este sostenía: "Para esto es necesario pensar en la reconstrucción de los ejidos, procurando que estos sean inalienables, tomando las tierras que se necesiten para ello, de las grandes propiedades circunvecinas, ya sea por medio de compra, ya por medio de expropiación por causa de utilidad pública con indemnización, ya por medio de arrendamientos o aparcería forzosos". ${ }^{32}$

Entre 1915 y 1924 según Gómez Santana se resolvieron definitivamente los procesos de repartición de tierras en 26 municipios en los cuales hubo 46 pueblos de Jalisco distribuidos, a saber: seis de Tlajomulco de Zúñiga, cinco en Zapotlán del Rey, cuatro en Chapala y el mismo número en Poncitlán, tres en Ocotlán y Tala respectivamente y dos en Limón; en los cuales fueron entregadas a 12.142 beneficiarios que recibieron $70.290 \mathrm{~h} .{ }^{33}$ Todo indica que esta autora solo clasificó las solicitudes que fueron finiquitadas o resueltas, digo esto porque la primera solicitud de la comunidad de Tequila fue realizada desde 1915 pero su resolución definitiva data de 1929. Más adelante, proporciona una cuantificación un tanto diferente sobre la tierras repartidas en Jalisco, que sostiene que entre 1918 y 1924 hubo 54 resoluciones definitivas en Jalisco afirmando que se repartieron $91.799 .6 \mathrm{~h}$ a 14.423 beneficiarios; o sea una cifra bastante más abultada que la más arriba mencionada. La diferencia en la cuantificación se debe a que recopiló las cifras en fuentes distintas, las primeras provienen del Registro Agrario Nacional y las segundas del Diario Oficial de la Federación.

El artículo de Angélica Navarro O. y Ramón Goyas M., ${ }^{34}$ es en gran medida un estudio que podría clasificarse como estructural, en la tradición de la larga duración braudeliana, porque su temporalidad abarca tres periodos de la historia de una región del actual estado de Jalisco, a saber: desde mediados del siglo XVIII hasta 1925. Su hipótesis sostiene que el despojo de tierras a las comunidades indígenas comenzó en la época colonial, continuó en el siglo XIX y comienzos del XX hasta que la ley zapatista redactada por Luis Cabrera, de enero de 1915, hizo posible que

\footnotetext{
${ }^{32}$ Citado por la autora de Luis Cabrera, La obra política de Luis Cabrera, compilado por Eugenia Meyer, UNAM, 1992, p. 483.

33 Gómez Santana, L., 2009, “Identidades locales y la conformación...”, pp. 73, 75-76.

${ }^{34}$ Navarro Ochoa, A. y R. Goyas Mejía, 2013, "La tierras de los pueblos en la región Valles de Jalisco, de la Independencia a la Revolución Mexicana", revista Estudios Agrarios, Procuraduría Agraria. https://www.pa.gob.mx/publica/rev 53-54/analisis/las tierras.pdf
} 
campesinos, indígenas y pobladores empezaran un proceso de recuperación de sus tierras vía restitución de las mismas y si esa ruta no era posible, vía dotación. La atención de los autores se centra en el largo y sinuoso proceso de apropiación de tierras comunales por parte de hacendados y terratenientes con la complicidad de las autoridades locales de la región Valles. ${ }^{35}$ Antes de la independencia hubo medidas tendientes a parcelar las tierras comunales y transformarlas en propiedad privada; estas se intensificaron en la primera mitad el siglo XIX y en la segunda parte con el triunfo del modelo liberal y la promulgación de las leyes de Reforma de 1860 que obligaban a la descorporativización de las tierras comunales y de los ayuntamientos, más las de colonización de terrenos baldíos facilitaron que los indígenas dividieran sus tierras y que las fueron perdiendo por los más diversos métodos legales e ilegales para llegar a manos de los grandes propietarios de la región, fue así que a través de ventas forzadas, deudas impagas, expansión ilegal de los límites de las haciendas hacia tierras que no eran suyas -obviamente, con la anuencia de las autoridades locales o con su omisión-, las comunidades fueran perdiendo poco a poco considerables extensiones de tierras laborables de riego, de temporal y de monte. ${ }^{36}$ Es así que a finales del Antiguo Régimen, la región Valles contabilizaba $63.430 \mathrm{~h}$ bajo propiedad indígena y entre 1915 y 1921 las comunidades solo detentaban 5.703 h en propiedad comunal. Entre 1922 y 1931 los solicitantes de dotación solo obtuvieron $38.107 \mathrm{~h}$ de tierras de temporal, riego y monte. Sale sobrando aseverar que la fragmentación y posterior despojo de tierras en la región Valles fue monstruosa. En lo que se refiere a Tequila los autores afirman que, en las mismas etapas señaladas líneas arriba, esta ciudad poseía en comunidad $2.535 \mathrm{~h}$ a finales del virreinato y solo 394 hectáreas en 1915. Cuando solicitaron tierras se les concedieron 1.712 h vía dotación en $1929 .{ }^{37}$ No queda sino preguntarse, como también lo hicieron estos autores, ¿por qué estos indígenas o pobladores no se levantaron en armas entre 1910 y 1914 como otros de diversos espacios territoriales del país?

\footnotetext{
35 Ibid, la región estudiada la constituyeron los siguientes municipios: Hostotipaquillo, Tuitlán, Tequila, Magdalena, San Marcos, Ezatlán, San Juanito, Ahualulco, Teuchitlán, Ameca, Tala, Ahuisculco, San Martín, Amatitán, y Cocula, pp. 177-197. Agregaría que lo aseverado por ellos en relación al despojo no difiere demasiado de lo ocurrido en la mayor parte del país donde habitaron los pueblos originarios.

${ }^{36}$ Estos autores señalan que el total de tierras propiedad de la familia Cañedo a fines del siglo XIX fue de 30000 hectáreas si se cuentan haciendas y ranchos, sus nombres eran: El Cabezón, Buenavista, La Vega, La Calera, Trapiche de Abra, Agua Caliente, Labor de Medina, San Antonio Matute, Santa María de la Huerta, Los Amiales, La Esperanza, Jayamitla y Quila. Agregaría que este complejo dista de ser una unidad, en otras palabras, fue propiedad dispersa, como solía suceder en el centro del país.

${ }^{37}$ Navarro Ochoa, A. y R. Goyas Mejía, 2013, “La tierras de los pueblos en la región Valles de Jalisco.., pp. 180, 184, 191.
} 
Otro texto, también de los mismos autores ${ }^{38}$ que ayuda a entender el proceso de reforma agraria en Jalisco, se refiere a la desintegración de la hacienda El Cabezón en el valle de Ameca y la subsecuente conformación de los ejidos con las tierras expropiadas a la familia Cañedo. En sí, con base en una investigación documental exhaustiva, narran brevemente la conformación del latifundio desde la época colonial y luego el largo proceso de lucha de los campesinos ${ }^{39}$ por lograr primero la restitución y cuando esta fue descalificada por la autoridad, la dotación de tierras, que finalmente lograron entre los años 1916 y 1939. En estos veintitrés años se distinguen claramente tres etapas, una, que fue entre 1916 al 1919, en la cual se dotó de tierras al Ejido San Martín con solo de 901,60 h; dos, otra entre 1920 a 1934 en que los campesinos no obtuvieron nada por las hábiles estrategias de los Cañedo para impedirlo; tres, la del triunfo que va de 1935 a 1939 en que los campesinos logran la dotación de 22.900,83 h. Entre las estrategias de los propietarios estuvieron, descalificar a los solicitantes porque eran peones acasillados empleados en sus propias tierras; obligar a los peones o jornaleros a firmar el desistimiento en sus solicitudes de dotación de tierras; dividir artificialmente la propiedad y objetar los censos agrarios realizados, señalando que muchos de los censados no eran habitantes del lugar ni nunca trabajaron la tierra. Es importante recordar lo que los autores apuntan que el proceso de reforma agraria estuvo repleto de conflictos entre campesinos y el propietario, y más tarde, cuando ya estuvieron formados los ejidos los pleitos de límites entre ellos terminaron en enfrentamientos y en muertes de un grupo o de otro. Cito a los autores: "con la distribución de la tierra se creó un campesino minifundista de subsistencia, cada vez más descapitalizado, cuyas familias hoy [artículo publicado en 2015] en día tienen que ampliar las formas de obtención de recursos para [...] el hogar." ${ }^{40}$

Hirineo Martínez Barragán y Myrna Quiñones Aguirre, ${ }^{41}$ abordan la reforma agraria en Jalisco, entre 1918 y 1922, desde la óptica de la cartografía. Pienso que es un trabajo de inmensa utilidad para entender cómo se elaboraron las diversas representaciones cartográficas del reparto de tierras a diversas comunidades jaliscienses entre los años señalados líneas arriba y por supuesto ayuda a explicar al lector la representación cartográfica de la reforma agraria en Tequila que proporciono en este trabajo. Permite además relacionarlo con él de Helga Baitenmann, porque coincide con la hipótesis planteada por ella en relación a la legislación y

\footnotetext{
${ }^{38}$ Navarro Ochoa, A. y R. Goyas Mejía, 2015, “Desintegración de la hacienda y conformación de ejidos en el valle de Ameca, Jalisco. El caso de la hacienda El Cabezón”, revista Secuencia, № 92.

${ }^{39}$ Los autores usan el concepto sin cuestionarlo.

${ }^{40}$ Navarro Ochoa, A. y R. Goyas Mejía, 2015, “Desintegración de la hacienda y conformación de ejidos en el valle de Ameca, Jalisco. El caso de la hacienda El Cabezón”, revista Secuencia, N 92, pp. 164-165.

${ }^{41}$ Martínez Barragán, H. y M. Quiñones Aguirre, 2013, "La cartografía de la reforma agraria en la época temprana: Jalisco, 1918-1922", en Historia locales en tiempos globales, Irma Beatriz García Rojas, (Coord.), Guadalajara, Universidad de Guadalajara/Plaza y Valdés Editores.
} 
normativa de dicha época que salió del ámbito judicial para situarse en el poder Ejecutivo administrativo. Los autores señalan que fueron necesarios una gran cantidad de agrimensores (topógrafos en la actualidad) e ingenieros para la métrica de las tierras susceptibles de ser afectadas desde la promulgación de la ley del 6 de enero de 1915.

Para estos autores el modelo de reparto de tierras obedeció sobre todo a lo efectuado en la práctica por el movimiento encabezado por Zapata en Morelos, donde el concepto de restitución pasó a ser la idea madre y el mecanismo más efectivo de recuperar las tierras despojadas. También este proviene de las ideas agraristas plasmadas en la constitución donde surge el modelo de dotación de tierras a quienes las solicitaran y demostraran que las necesitaban y habitaban en los lugares.

Según Martínez Barragán y Quiñones Aguirre en Jalisco:

"el reparto de tierras constitucional inició en 1918 con el ejido de Santa Clara del Pedregal, municipio de Ocotlán y concluyó en 1991. [...] En este proceso se promovieron 2.056 acciones agrarias que quedaron registradas a lo largo de 63 años; de los cuales 1.236 fueron dotaciones de ejido a otros pueblos, además se restituyeron tierras en diferentes modalidades a 52 comunidades generalmente indígenas, se produjeron 549 ampliaciones y 111 segundas ampliaciones." ${ }^{42}$

Hasta aquí la revisión historiográfica de las obras que han narrado, descrito e interpretado el proceso de la reforma agraria en Jalisco al cual agrego -a continuación- un trabajo fundamental relativo a la legislación nacional que se implementó para hacer posible la transformación de la estructura de la propiedad de la tierra en México.

La legislación administrativa fuera de los tribunales de justicia que dominó la puesta en práctica de la reforma agraria en el país después de la ley Cabrera de enero de 1915, es parte central del artículo de Helga Baitenmann. Sin embargo, a esta la precede una descripción histórica del ejercicio de la justicia en México durante el siglo XIX en materia de juicios por disputas, litigios y conflictos de tierras (entre hacendados y comunidades, entre comunidades y entre pueblos) y cómo esta cambió, con decretos leyes que la autora caracteriza como revolucionarios ${ }^{43}$-lo fueron sin duda-, que permitieron que la justicia y pleitos por tierras salieran del ámbito del poder judicial de la nación y fueran llevados al administrativo, en virtud del nuevo poder adquirido por el ejecutivo que hizo posible que para asuntos de restituciones

\footnotetext{
42 Ibid, p. 143.

${ }^{43}$ Baitenmann, H. 2017, "Ejerciendo la justicia fuera de los tribunales: de las reivindicaciones decimonónicas..: Ley del 6 de enero de 1915. Fracción VII del artículo 27 de la constitución de 1917 que decía "todas las leyes de restitución son de inmediata ejecución por autoridad administrativa" (p. 2054). "En cuanto a la indemnización la Suprema Corte permitió la expropiación de tierras y aguas privadas sin previa compensación para dotar a pueblos necesitados," p. 2058.
} 
y dotaciones de tierras, se crearan instancias administrativas resolutivas, incluso, especies de tribunales agrarios que llevaron a cabo la reforma de las tierras propiedad de grandes $y$ medianos latifundistas del país. ¿Por qué? Porque durante el siglo XIX, las diversas instancias del poder judicial mostraron poco interés, lentitud y omisión en la resolución de los litigios de tierras de los que reclamaron despojo, apropiación ilegal o ventas forzadas de las mismas, favoreciendo con ello al segmento social constituido por los grandes propietarios; para muestra un botón: líderes de Xilotepec, Edo. De México, afirmaron en 1911, "que la defensa de nuestros intereses ha sido o mal hecha por las influencias de ricos o ahondadas por nuestra falta de recursos para pagar a nuestros abogados." ${ }^{44}$ Visto desde la óptica política, según Baitenmann, fue "un reajuste de las facultades y competencias entre los poderes Ejecutivo y Judicial [que] permite revalorar las ideas dominantes sobre el momento fundacional del derecho agrario y los orígenes del autoritarismo presidencial mexicano del siglo XX."45

Fue en este contexto que se crearon instancias y órganos que respondieran directamente al poder ejecutivo como: la Comisión Nacional Agraria, las comisiones locales agrarias y se otorgó al gobernador de cada estado la facultad de dar el fallo final a la restitución o dotación de ejidos, una vez que el proceso de expropiación hubiera terminado completamente. $\mathrm{O}$ sea, se formaron verdaderos tribunales administrativos. Fue así como la medición de las tierras objeto de expropiación fueron entregadas a ingenieros y agrimensores nombrados por la Comisión Local Agraria.

\section{Proceso de reforma agraria en Tequila}

\section{La restitución y su fracaso, 1915-1920}

El proceso de reforma agraria en Tequila ${ }^{46}$ como en la generalidad del Estado de Jalisco comienza más menos en 1915 , después que en enero se promulgó la ley que autorizó a la población de pueblos, fueran indígenas o no, a pedir o solicitar a las instancias legales correspondientes, la restitución y dotación de tierras. En septiembre de ese año, Luciano Hernández, en representación de la comunidad indígena -así se autodenominó- del municipio de Tequila, dirige a la Secretaría de Gobierno de Jalisco la solicitud de restitución de tierras que

\footnotetext{
44 Ibid, p. 2032.

45 Ibidem, p. 2016.

46 La Comisión Agraria de Jalisco transcribió en un solo legajo toda la información documental relativa a los procedimientos llevados a cabo para aplicar leyes y decretos con el fin de implementar la reforma agraria en Tequila. Este documento tiene 94 páginas mecanuscritas que narran con lujo de detalle la solicitud de restitución y luego de dotación de tierras realizada por la comunidad indígena de Tequila, ante la Secretaría del Supremo Gobierno del Estado de Jalisco, vía Comisión Agraria desde 1915 hasta 1929, año de resolución definitiva." En lo que sigue de dicho expediente se agrega un Resumen escrito de todo el proceso de reforma agraria de Tequila. Además, utilicé otros dos documentos completos: 1ạ Ampliación Expediente $N^{\circ} 937$ y Expediente 2a ampliación 1980. Todos disponibles para quien desee consultarlos en el Archivo de la Comisión Agraria de Jalisco.
} 
desde tiempos ancestrales fueron de su propiedad, alegando arbitrariedad de los gobiernos anteriores que actuaron de "consuno con los acaudalados [que] nos han postergado, humillado, sumergido y despojado, aprovechándose sin acción [de] nuestras tierras y montes, hemos querido permanecer como lo hacemos, quietos y callados, hasta no tener las garantías de integridad y orden que necesitamos. ${ }^{\prime 47}$ Las tuvieron a partir de $1915,{ }^{48}$ como resultado del movimiento revolucionario de 1910 y la legislación protectora que le siguió; en virtud de ella procedieron a reclamar la propiedad y restitución de las tierras que comprendían la cima del cerro Tequila y un perímetro bastante amplio, cuyo sustento legal residió en la antigua disposición virreinal de 1803.

Lamentablemente el juicio se prolongó por varios años sin que se obtuviera una resolución favorable para los indígenas. En 1918 la comunidad vuelve a la carga, exigiendo la restitución de sus tierras con base en la misma disposición virreinal de 1803. En este año la solicitud varía en algunos puntos; dice al calce:

"Los indígenas del pueblo de Tequila, 12 cantón del estado, fundados en los títulos que exhibieron [en] la ley del 6 de enero de 1915, han solicitado al señor gobernador del estado, restitución de medio sitio de ganado mayor [...] en la cima del cerro de Tequila y los siguientes predios:- Banco Grande, Banco Chiquito, Plan de los Muchos, Cruz de Madroño, Arroyo de la Tinaja, Cuesta Alta, Cerrito del Agua Fría, Cabeza de Buey, Costa del Jicote, Cuesta del Capulín, Plan de Valdéz, San Marcos, Plan de los Cigarros, Ojo de agua Carrizo, Meza de los Guajolotes, Meza de Valdez, Los Pocitos, Meza Colorada, Cerrito del Roble, Ciénega hasta el Arroyo de la Canoa, Cerrito de Chiquihuitillo, Ojo de Agua del Venado, Agua Blanca, Chiquita hasta el Arroyo de la Canoa, Joyanco Grande, Plan de la Tronconera, Plan de Alba, Ojo de Agua Blanca Grande, Plan de las Víboras, Plan de Cañedo, Plan de las Cruces, Plan de los Tambores, El Boyadero, y la mitad izquierda del Cerro." 49

Los argumentos centrales de los solicitantes de restitución de tierras radicaron en la arbitrariedad con la que actuaron en 1882 la comisión repartidora y Carlos Gómez su presidente, momento en que se aplica en Jalisco la ley de descorporativisación de tierras de dicho año. Según los escritos entregados por los indígenas este señor no actuó con honradez ni consultó con ellos cuál de las dos mitades en disputa del cerro de Tequila deseaban mantener bajo su propiedad. La mitad derecha era la parte baja con mejores tierras y la izquierda la alta, de menor calidad. Por supuesto, tanto la comunidad como los propietarios individuales quisieron la misma 'manzana', lo que generó la discordia.

\footnotetext{
47 AAAEJ, CLA, Exp. 34, p. 2.

${ }^{48}$ La ley del 6 de enero de 1915 en su Artículo $3^{\circ}$.

${ }^{49}$ AAAEJ, CLA, exp. 34, p. 5.
} 
La narrativa indígena señala que dicha comisión repartidora de 1882 "se puso de parte de los adinerados;" ${ }^{50}$ sea por soborno, sea por parentesco o por ambas razones, lo cierto fue que los grandes propietarios interesados en las tierras llevaron a cabo el despojo. Entre ellos estuvieron Cenobio Sauza Madrigal, al que se acusa de haber falseado nombres de personas o de plano nombrar "infinidad" de individuos ausentes y fallecidos, de los cuales él era depositario de sus tierras. Estos procedimientos permitieron a Cenobio Sauza apropiarse de los terrenos Banco Grande, Banco Chiquito, Plan de los Muchos y Cruz de Madroño, el Ganeño y El Boyadero. Además, alegó haber comprado y tener en posesión Arrollo de la Tinaja, La Cuesta Alta y Cerrito de Agua Fría, situación que se agudizó cuando él mismo fue presidente municipal, pues además de declararse propietario de las tierras indígenas, "hizo grandes destrozos de los montes [...] arrojó por completo de sus terrenos a la comunidad. [...] Para lanzar a los indígenas de sus terrenos [....] bastó la sola orden que se les dio a lo que nadie trató de oponerse porque iba de por medio su vida." ${ }^{51}$ Por si faltara, cuando alguno se atrevía a sustraer de dichos terrenos leña, la policía la decomisaba, los detenía y encarcelaba por uno o dos meses. ${ }^{52}$

La lista de los beneficiarios del despojo de tierras iniciado en 1882, además de Cenobio Sauza es la siguiente: Jesús Flores, José Cuervo, Antonio Jiménez, José María Castañeda, Francisco Romero y Catalina A. de Romero, quienes fundaron "sus derechos en acciones compradas a los mismos indígenas y en la quieta y pacífica posesión de varios años." ${ }^{\prime 53}$

Acorde a las disposiciones de la ley de enero de 1915, los propietarios de las tierras susceptibles de ser expropiados, tuvieron el derecho de defender los títulos de propiedad legal que tenían sobre ellos y, por supuesto, argüir las razones para declarar estas tierras como inafectables. En relación a esto último, los propietarios sostuvieron que:

"los indígenas del pueblo de Tequila poseen extensas propiedades que no llegan a cultivar ni a aprovechar en debida forma y convenientemente; que esos indígenas son muy pocos y que con los terrenos que poseen tienen bastante para dedicarse, al desear trabajar, a cultivar sus propios terrenos y que dotarlos de mayor cantidad de tierras con mengua de los que hemos adquirido después de muchos años de trabajo y privaciones las pequeñas propiedades que poseemos, es no solo una injusticia, sino también provocar un atraso al progreso de la agricultura." 54

\footnotetext{
${ }^{50}$ AAAEJ, CAL, EXP. 34, p. 7.

${ }^{51}$ AAAEJ, CAL, EXP. 34, pp. 7-8.

52 Situación parecida sucedía con los obreros del carbón en las minas subterráneas de Lota, Concepción, Chile, descrita con lujo de detalles por Baldomero Lillo en Sub terra. Cuenta este autor que cuando alguien se aventuraba a comprar un artículo de consumo diario fuera de la "tienda de raya" de la mina y era sorprendido, era severamente castigado además de decomisarle lo comprado.

53 AAAEJ, CAL, EXP. 34, p. 79.

${ }^{54}$ AAAEJ, CAL, EXP. 34, p. 9.
} 
Otros factores de peso que hicieron valer los propietarios para la inafectabilidad fueron, en primer lugar, que Tequila no era un pueblo, sino una ciudad industrial con una gran actividad productiva muy rentable que lejos de estar en crisis disfrutaba de muy buena salud; ${ }^{55} \mathrm{y}$ dos, muchas de las propiedades eran menores a 50 hectáreas, por lo tanto, no podían ser objeto de restitución ni dotación; al respecto aseveraron que se oponían: "a la restitución intentada por los vecinos de Tequila, acompañando en copia certificada los títulos de las propiedades por ellos adquiridas y manifestando que sus predios constituían pequeñas propiedades, por lo que no procedía afectarlos, de conformidad con el artículo 27 constitucional." ${ }^{56}$ Los únicos poseedores de tierras que fueron reclamadas como materia de restitución o dotación y que respondieron a las notificaciones enviadas por la Comisión Local Agraria fueron los del cuadro siguiente:

Tabla 2. Individuos que hicieron la defensa de la titularidad legal de la posesión de sus tierras, 1918

\begin{tabular}{|c|c|c|c|}
\hline Año & Propietario & Tierras en propiedad & Superficie \\
\hline $1907-1914$ & Cipriano Rosales & La Muralla, Ojo de Agua & 20 h 34 á, 95 cá \\
\hline $1893-1896$ & Bonifacio Andalón & $\begin{array}{c}\text { El Platanillo, El } \\
\text { Choloaca }\end{array}$ & - \\
\hline Varios años atrás & Marco Rosales & El Castillo, Ojo de Agua & Menos de $50 \mathrm{~h}$ \\
\hline Varios años atrás & Roberto Rosales & $\begin{array}{c}\text { Los Colgados, Los } \\
\text { Jarritos, La Ladrillera }\end{array}$ & - \\
\hline Varios años atrás & Abel García & El Tempizque & - \\
\hline 1900 & José Cuervo & $\begin{array}{c}\text { La Villa, Las } \\
\text { Juntas,Mochitiltic }\end{array}$ & $\begin{array}{c}\text { Más de } 79 \text { h, } 99 \text { á, } 68 \\
\text { cá }\end{array}$ \\
\hline 1893 & Cenobio Sauza & $\begin{array}{c}\text { Terreno Junta de los } \\
\text { Arroyos }\end{array}$ & $\begin{array}{c}2 \frac{1}{2} \text { fanegas de } \\
\text { sembradura }\end{array}$ \\
\hline 1899- 1912 & Enrique Aguirre 57 & $\begin{array}{l}\text { Predios La Cofradía, Los } \\
\text { Tepetates, La Culebra, } \\
\text { La Loma } \\
\text { Terreno Toma de Agua. } \\
\text { Predio Los Guajes }\end{array}$ & $\begin{array}{l}417 \text { varas al poniente; } \\
234 \text { 1/2 v al este; } 267 \text { v } \\
\text { al sur; } 350 \text { v al norte. } \\
1 \text { há, } 68 \text { á, } 82 \text { cá }\end{array}$ \\
\hline $1899-1903$ & Epitacio Alva & $\begin{array}{c}1 \text { terreno: Pajaritos, } \\
\text { Toma de Agua y Salto } \\
\text { de Aguacero }\end{array}$ & $1 \mathrm{~h}, 68$ á, 82 cá \\
\hline 1906 & $\begin{array}{c}\text { Ignacio Romero } \\
\text { Aguilar }\end{array}$ & Terreno El Zopilote & $3 \mathrm{~h}$ \\
\hline
\end{tabular}

Fuente: Elaboración propia, Archivo Histórico Agrario, Jalisco, Exp. 34, Comisión Local Agraria, Tequila, Legajo restitución de tierras, pp. 9-34v.

\footnotetext{
${ }^{55}$ Uno de los argumentos fuertes de los propietarios y autoridades residía en que al ser ciudad con autoridades propias en cada ayuntamiento, las comunidades indígenas perdían todos sus derechos como pueblos eliminando de tajo las propiedades comunales y los derechos de autonomía pues estos recayeron en las cabeceras municipales.

${ }^{56}$ AAAEJ, CLA, EXP. 34, Resumen, p. 1.

${ }^{57}$ Este heredó numerosas propiedades urbanas de su padre León Aguirre en Tequila.
} 
Los argumentos expuestos por los propietarios en relación a la legalidad con la que adquirieron sus propiedades descansan en la vista de copias certificadas de protocolos notariales de compraventas que acreditaban dicha situación; sosteniendo por lo tanto que sus tierras no eran objeto de restitución reclamada por los indígenas.

En 1918, continuando con el relato, un perito paleógrafo nombrado por la Comisión Nacional Agraria examinó, revisó, cotejó y dictaminó la autenticidad de los documentos (copias de expedientes) presentados por la comunidad indígena a fin obtener la autorización del Estado para la restitución de sus tierras y formar un ejido. El dictamen sostuvo que el testimonio era legal. ${ }^{58}$

Después de seis años de gestiones fallidas, en 1921, el derecho de restitución de tierras fue denegado a la comunidad indígena de Tequila. La razón argüida en el documento señala que esta no pudo comprobar que efectivamente fue despojada de sus tierras, entonces se procedió a la ejecución de la otra alternativa: la dotación de tierras. Esta solicitud fue apoyada por la Comisión Nacional Agraria y también por la Local quienes desestimaron uno de los argumentos centrales de los propietarios tequileros, al señalar que:

"si bien la industria de alcohol de Tequila, no ha ido a menos, está en la conciencia pública que pronto las ideas moralizadoras modernas podrán contrarrestar las influencias de los acaudalados fabricantes de esa embriagante bebida, causa principal de la degeneración de nuestro pueblo, y en consecuencia esa industria tiene que ir a menos o que desaparecer y aun suponiendo sin conceder, que como lo aseguran los terratenientes, aquellas tierras las siembran de mezcal porque no producen otra cosa, al prohibir la fabricación del alcohol, tendrán que dedicar dicha planta o cualquiera otro agave a la industria textil, con seguridad menos remuneradora que la del tequila, trayendo en un futuro próximo, una decadencia de esa fuente de riqueza que por hoy ha hecho enormemente ricos a determinados terratenientes, no pudiendo los moradores pobres de aquella región sino ser braceros explotados y degenerados." 59

\section{Proceso de dotación, 1922-1929}

Fue el ingeniero Manuel López Ángel el que llevó a cabo su trabajo como sigue: recorrió la zona para darse cuenta de las distintas propiedades, accidentes y naturaleza del terreno, a fin de

\footnotetext{
${ }^{58}$ Acorde a la legislación de la Comisión Nacional Agraria, la comunidad indígena debió nombrar al presidente, secretario y tesorero del Comité Particular Ejecutivo, instancia que ayudaba y apoyaba las actividades necesaria para llevar a cabo el procedimiento de restitución de las tierras. Estas responsabilidades no estuvieron exentas de conflicto y hubo varios cambios a raíz de que los indígenas perdían la confianza en el buen proceder de algunos de ellos, sea porque se aprovechaban del cargo en beneficio propio y su familia, sea por el mal manejo de los fondos recaudados por toda la comunidad o por ambos motivos. Dichos representantes fueron reemplazados por lo menos en tres ocasiones entre 1915 y 1921.
}

${ }^{59}$ AAAEJ, CAL, EXP. 34, p. 81. 
ordenar del mejor modo posible las operaciones de campo por ejecutar; luego, la medición angular la realizó con un teodolito Heller y Brighty, con el objetivo de planificar la zona. De este proceso resultó el trazo de un polígono que incluyó todas las propiedades pequeñas y a partir de este los restantes otros 20 con los terrenos de diversos grandes propietarios, obviamente, con extensiones mayores a las 50 hectáreas. M. López Ángel explicó técnicamente que:

"Los procedimientos adoptados por mí para fijar la mayor de los detalles fueron los de radiaciones, intersecciones y los que más generalmente se usan en los trabajos de la naturaleza del que me ocupo. Dentro del perímetro general fijé todos los accidentes que creí necesarios para completar hasta donde fuera posible la representación topográfica de la zona ya citada. La orientación astronómica se hizo por la culminación superior de la polar sobre el lado 0-1 del polígono principal." 60

Luego procedió a elaborar el plano heliográfico respectivo a una escala de 1 a 20.000 que tuvo como base uno anterior elaborado por el ingeniero Salvador Cuellar; dicho plano tuvo como centro la ciudad poblada y a su alrededor se midió una superficie de $12.000 \mathrm{~h}$ que en teoría abarcaba los 21 polígonos planificados para con posterioridad formar ejidos (ver mapa final). El plano incluyó los siguientes potreros y terrenos:

Tabla 3. Zona circundante a Tequila susceptible de afectación, 1922

\begin{tabular}{|l|l|}
\hline Nombre del propietario & Nombres del potrero o terreno \\
\hline Hermanos Andalón & Jonacaste, Choloaca \\
\hline Miguel Flores & Maloaste, Las Trojes, Las Cárdenas, La Cocolia, El Novillero, El Zalate \\
\hline $\begin{array}{l}\text { Ana González Rubio vda. } \\
\text { De Cuervo }\end{array}$ & El Trapiche, El Grillo, El Retiro, El Istetal \\
\hline Eladio Sauza & $\begin{array}{l}\text { Las Mojoneras, El Novillerito, El Barroreño, El Cuije Bojeño, San } \\
\text { Francisco, San Antonio, Lomas de la Gloria, Santa María, El Tecolote, El } \\
\text { Novillero, El Camichín, El Algodón y El Ocote, El Guarreño, Las Víboras, } \\
\text { El Jacoatole, San Pedro, y casco de la hacienda Medineño }\end{array}$ \\
\hline Luis Sauza & $\begin{array}{l}\text { La Mula, El Derramadero, Las Teposas, Las Presas, La Tijera, El } \\
\text { Hundidero, Las Torrecillas, El Novillero y Las Tapias, La Mesa Grande, } \\
\text { Las Cruces, El Novillero, Potrero Grande, La Puerta de En medio }\end{array}$ \\
\hline Miguel Rosales Armas & $\begin{array}{l}\text { El Novillero Chico, El Tejero, El Rancho de la Cantera, El Tepehuaje, } \\
\text { Lomas del Calvario, El Sabino }\end{array}$ \\
\hline
\end{tabular}

Fuente: Elaboración propia, AAAEJ, CLA, EXP. 34, Resumen final, pp. 2-2v. Zonificación realizada por el ingeniero Manuel López Ángel.

En ese momento no se tuvieron en cuenta los valores catastrales ni comerciales de los predios mensurados; tampoco la calidad de las tierras ni mucho menos las propiedades que

${ }^{60}$ AAAEJ, CAL, EXP. 34, p. 58. 
serían afectadas con la reforma. Pero sí se acordó que para concretizar la dotación era necesario afectar al menos un $5 \%$ de las tierras de los grandes propietarios.

La oficina de la Administración de Rentas de Tequila proporcionó a la Comisión Nacional Agraria y a la Comisión Local jaliscienses los datos duros sobre los propietarios con extensiones mayores de 50 hectáreas, resultaron ser los siguientes:

Tabla 4. Grandes propietarios de Tequila, 1921, 1923

\begin{tabular}{|l|l|l|}
\hline Propietarios & $\begin{array}{l}\text { Medida en hectáreas, } \\
\text { áreas, centiáreas 1921 }\end{array}$ & $\begin{array}{l}\text { Medida en hectáreas, } \\
\text { áreas, centiáreas 1923 }\end{array}$ \\
\hline Sucesión José Cuervo & 3.358 .55 .44$. & \\
\hline Miguel Flores y condueños. & 1.905 .99 .57 & $3,315.23 .39$ \\
\hline Apolonio García & 1.478 .00 .00 & \\
\hline Ana González Rubio Vda. de Cuervo & 5.655 .01 .00 & $7,482.56 .44^{61}$ \\
\hline María Jiménez de F. & 1.409 .34 .00 & \\
\hline Sucesión Cenobio Sauza & 9.171 .00 .00 & 9,171 \\
\hline Miguel Rosales Armas & 4.533 .64 .00 & $4,833.64 .00$ \\
\hline
\end{tabular}

Fuente: Elaboración propia, Archivo Histórico Agrario, Jalisco, Exp. 34, Comisión Local Agraria, Tequila, Legajo restitución de tierras, p. 80v. Resumen final, p. 5.

El documento asevera que el conjunto de propiedades susceptibles de ser afectadas suma 24.803 h, 43 á y 83 cá. ${ }^{62}$ Concluye además que para completar la dotación son necesarias expropiarles a estos aproximadamente $1.200 \mathrm{~h}$.

Las tierras afectables fueron clasificadas en dos clases, las del plan que en su totalidad eran de temporal y de pasto, y las altas conformadas por lomeríos y cerro; estas eran de inferior calidad y estaban cubiertas de pedacería de obsidiana y piedra volcánica. Según el documento la dotación debía comprender tierras de las dos calidades. En las tierras altas solo era posible el cultivo del maguey y en las otras más bajas se producía: maíz, camote, cacahuate, frijol, trigo, garbanzo, patata, durazno, mostaza, chayote, nopal manso, membrillo. La vegetación espontanea de las tierras afectables era diversa, se encontraban: abrojo, enciso, pini, papalote, roble, guamúchil, huizache, tepame, copal, negrito, pinabete, majahua, rosa maría, santa maría, tepezapote, ahuilote, guayabo, vara dulce, salvia, tepopote, ciruelo. ${ }^{63}$

\footnotetext{
${ }^{61}$ En 1923 las propiedades de la señora Ana González Rubio viuda de Cuervo se sumaron a las de la Sucesión José Cuervo y ya habían "sido afectadas con 1.150 hectáreas para Magdalena", AAAEJ, CLA, Exp. 34, Resumen final, p. 5. 62 Dicha suma no concuerda con la del cuadro anterior, situación que se explica porque la hacienda San Antonio cuyo dueño era Apolonio García no fue afectada pues "está formada en su mayor parte por una barranca en que se cultiva café y frutales, y tiene además una planta hidráulica [que] está en mi concepto exceptuada conforme a lo dispuesto por el artículo 18 del reglamento vigente, así como también porque no tiene tierras laborables." AAAEJ, CLA, Exp. 34, p. 82 y Resumen final, p. 5.
}

${ }^{63}$ AAAEJ, CAL, EXP. 34, p. 2. 
Antes de efectuar la dotación de tierras, como era usual, se llevó a cabo primero un censo agrario de los habitantes del municipio de Tequila, acorde a lo dispuesto en los artículos 12, 22 y 23 del Reglamento Agrario expedido por el presidente de la república el 10 de abril de 1922. Para hacerlo se nombró en asamblea de la comunidad agraria a su representante, cargo que recayó en Mateo Castañeda, electo por unanimidad y la Comisión Local Agraria nombró como vocal comisionado para la misma tarea. El municipio también nombró a un regidor como su propio representante.

Por razones de espacio es imposible transcribir el censo agrario, pero sí enumerar algunos de sus perfiles más señeros. Fueron 340 individuos censados, de ellos $56 \%$ eran hombres y $44 \%$ mujeres. Las edades de los censados iban desde 4 meses a 66 años de edad y contabiliza "106 jefes de familias, muchas mujeres y menores de 18 años." ${ }^{64}$ El 31\% expresó su ocupación, entre los cuales hubo: un carpintero, un curtidor, un herrero, un obrero y 99 jornaleros. Es de notar que ninguno es nombrado como campesino o indígena. El 60\% del total manifestó su estado civil, por obvias razones todos los menores de quince años fueran hombres o mujeres que tienen ese registro en blanco. Si se comparan los apellidos apuntados en el censo o padrón de 1922 con los de los firmantes que solicitaron restitución de tierras en 1918 y dotación en 1921, coinciden solo algunos, para ser exacta: solo 16 apellidos.

Demás resulta decir que una copia de este padrón fue entregado a los propietarios susceptibles de ser afectadas sus tierras, quienes debieron hacer las observaciones y objeciones que les parecieran pertinentes en un plazo limitado de diez días. Lo hicieron y de manera contundente rechazaron la veracidad de los datos capturados en el censo, no por quienes lo levantaron sino por los que proporcionaron los empadronados. Las objeciones se resumen así: 1) Tequila tiene la categoría de ciudad no es un pueblo. 2) Posee una boyante industria vinera que no está en crisis, al respecto cito: "Probablemente no hay población en el Estado que tenga un carácter industrial más marcado, sin que haya sufrido la industria demérito alguno, ni haya disimulado (sic) su población.- Por lo mismo, y de conformidad con lo dispuesto por la fracción VII del artículo 1으 del regl., no puede solicitar ni obtener tierras." 65 3) El padrón no es acorde a la verdad pues muchos de los individuos no son vecinos de la ciudad, ni mucho menos todos son jornaleros. 4) El censo nunca debió haber sido levantado, fueron los agraristas quienes

\footnotetext{
${ }^{64}$ En página 5 del mismo documento anotado en la referencia archivística anterior contiene un resumen de todo el proceso de reforma de la estructura de propiedad de la tierra en el cual se asevera que: "Documentación relativa a la rectificación de que fue objeto el censo agrario, en atención a las observaciones formuladas por los propietarios de las fincas afectables. En virtud de dicha rectificación, quedaron excluidos por diversas causas 12 individuos que figuraban en el censo primitivo y habiéndose comprobado que 23 vecinos del poblado, en la fecha de la rectificación llenaban, tanto por su edad como por su condición económica, los requisitos que la ley exige para tener derecho a tierras, hubieron de agregarse estos 23 individuos, por lo que el censo agrario arroja en definitiva un total de 117 capacitados para recibir tierras, entre jefes de familia y varones solteros mayores de 18 años."
}

${ }^{65}$ AAAEJ, CLA, Exp. 34, p. 72 
engañaron a la Comisión Agraria. 5) Ninguna de las propiedades puede ser objeto de afectación porque representan unidades agrícolas industriales en explotación. 6) Ni mujeres ni menores de 18 años debieron ser censados o empadronados. 7) "La comunidad agraria de Tequila existe de hecho en estado comunal, puesto que son poseedores de una extensión de terreno de 394 hectáreas que ellos mismos cultivan." ${ }^{\prime 66}$ 8) Por último, ya no sobre el censo sino sobre la ley, sostienen que no puede "pretender que los operarios de fábricas, artesanos, etc. abandonen sus ocupaciones para dedicarse al cultivo del suelo arrancado a la fuerza a quienes lo habían adquirido con título legítimo." 67

Las objeciones interpuestas por los propietarios fueron atendidas y turnadas al Juzgado de Primera Instancia de Tequila para que examinara las pruebas de lo afirmado por ellos. Para tal efecto interrogaron a seis testigos, todos antiguos vecinos de la ciudad y de respetables edades -entre 33 y 86 años- quienes atestiguaron lo que los propietarios aseveraban, a saber: que Tequila era una ciudad que había aumentado considerablemente su industria, su población, su comercio y, por supuesto, que la gran fuente de riqueza era la producción vinícola de tequila, por lo tanto, no había condiciones suficientes para que alguien tuviera el derecho a solicitar la creación de ejidos para los vecinos de Tequila.

En el transcurso de 1923 integrantes del Comité Particular Ejecutivo de la comunidad indígena de Tequila, el presidente municipal Malaquías Cuervo y el ingeniero Mariano Pérez Días en 1923, dictaminaron: "En nombre de la Ley de 06 de enero de 1915, de conformidad con el artículo 27 constitucional y cumpliendo así con la resolución dada por el Supremo Gobierno del Estado de fecha de 05/01/ del presente año, recibo y entrego a ustedes para su cultivo y bienestar del pueblo, las tierras concedidas por nuestras sacras leyes, representadas dignamente por los actuales mandatarios." A todo lo cual, el propio Comité Particular Administrativo contestó:-“Las tierras que ahora recibimos del Supremo Gobierno, como dotación, serán administradas con respetuosa honradez, procurando fomentar la agricultura en bien general del pueblo.-"[....] No habiéndose registrado ningún otro incidente, se levanta la presente acta que se firma por todos los que en ella intervinieron y que supieron hacerlo." ${ }^{\prime 6}$

\footnotetext{
${ }^{66}$ En p. 80 de este mismo documento se asevera lo siguiente: "está una propiedad cerrada, por un triángulo que, según parece, fue cedida a la comunidad por la casa Sauza y que tiene una extensión superficial de 394 h 78 á 50 cá y que los terrenos mejores para el cultivo del maíz, frijol etc. son los del cerro mencionado y lo contiguos a él."

${ }^{67}$ AAAEJ, CLA, Exp. 34, p. 75.

${ }^{68}$ AAAEJ, CLA, Exp. 34, p. 93.
} 
Tabla 5. Propietarios y tierras afectadas por la comisión local agraria para la dotación de la comunidad indígena de Tequila, 1923.

\begin{tabular}{|c|c|c|}
\hline Nombre del propieario & Nombre terrenos o potreros & $\begin{array}{c}N^{\circ} \text { de hectáreas } \\
\text { expropiadas }\end{array}$ \\
\hline Cuervo, Ana González vda. de & Las Tapias, El Novillero, El Grillo & $343 \mathrm{~h}$ 50 á \\
\hline Flores. Miguel y condueños & El Maluaste, De Abajo & 153 \\
\hline Rosales Armas, Miguel & Los Llanitos & 239 \\
\hline Sauza, Eladio & $\begin{array}{c}\text { El Gallino, El Tescalame, Las } \\
\text { Mohoneras, El Sencheño, El } \\
\text { Negrito }\end{array}$ & \\
\hline Sauza, Luis & El Novillero, La Mula & 162 \\
\hline Total & & 1.197 \\
\hline
\end{tabular}

Fuente: Elaboración propia, AAAEJ, CLA, Exp. 34, p. 93 y Resumen final, p. 4

Una vez realizado el dictamen y declarada legal la dotación de tierras, las reacciones de los propietarios no esperaron en ser expresadas para negarse a concretar la entrega de las tierras afectadas por la reforma. Los argumentos no fueron muy distintos de los ya expresados en el proceso legal de restitución primero y en el de dotación en segundo. El objetivo central era declarar el hecho como improcedente.

Desde el momento mismo en que los beneficiarios de la dotación comenzaron a tramitar sus expedientes para lograr las tierras que legalmente podían obtener, los propietarios afectados simultáneamente estuvieron presentando diversos alegatos, tendientes todos a la defensa de sus intereses, argumentando que sus fincas eran unidades agrícolas industriales en explotación; que las propiedades ya habían sido afectadas por lo tanto era injusto que volviera a repetirse; que los dotados habían tomado más tierras que les correspondían, que la industria del vino de tequila ha venido a menos y bajado su producción entre $50 \%$ y $60 \%$; "que los recursos industriales y comerciales en la población de Tequila han decaído de 6 años a la fecha, especialmente en lo que se refiere a la fabricación de vino tequila, en virtud de que se ha descuidado la plantación y cultivo de las mezcaleras." ${ }^{\prime 69}$

A pesar de los tiras y aflojas e indignación de los propietarios el gobernador del Estado en abril de 1927 declaró legal y acorde con las disposiciones de la Comisión Nacional Agraria la dotación de tierras a los jefes de familia que los solicitaron y obtuvieron, el documento dice:

"el artículo 27 de la constitución Federal categóricamente ordena que cuando la restitución no proceda se adjudiquen las tierras en calidad de dotación, sin que en ningún caso deje de asignarse a los pueblos las que sean necesarias para que sus moradores atiendan a su subsistencia y logren su mejoramiento económico y social; y como, además, los mismos solicitantes pidieron que se les dotara de tierras en virtud de carecer de ellas en lo absoluto;

${ }^{69}$ AAAEJ, CLA, Exp. 34, Resumen final, p. 7v. 
las autoridades agrarias siguieron la tramitación en la vía dotatoria habiéndose comprobado que la ciudad de Tequila cuenta con 117 individuos, entre jefes de familia y varones mayores de 18 años con derecho a ser dotados, que solo poseen una superficie de $394 \mathrm{Hs}$. de terreno cerril, que son marcadamente insuficientes para cubrir sus necesidades, estando, por lo mismo, la ciudad de Tequila, dentro de lo preceptuado por los arts. 3/o. de la ley de 6 de enero y 27 de la Constitución Federal, debiendo en consecuencia, declararse procedente y necesaria la dotación solicitada." ${ }^{70}$

Tabla 6. Propietarios y tierras afectadas por la comisión local agraria para la dotación de la comunidad indígena de Tequila, 1927

\begin{tabular}{|c|c|c|}
\hline Nombre del propietario & Nombre terrenos o potreros & $\begin{array}{c}N^{\circ} \text { de hectáreas } \\
\text { expropiadas }\end{array}$ \\
\hline Cuervo, Ana González vda. de & $\begin{array}{c}\text { Las Tapias, El Novillero, El Grillo, EI } \\
\text { Trapiche, El Istetal }\end{array}$ & 483 \\
\hline Flores. Miguel y condueños & Las Cárdenas, Las Trojes, El Maluaste & 235 \\
\hline Rosales Armas, Miguel & Ojo de Agua de la fundición, El Sabino & 343 \\
\hline Sucesión Cenobio Sauza & $\begin{array}{c}\text { San Antonio, San Francisco, La Mula, } \\
\text { La Mojonera, Mesa Grande }\end{array}$ & 651 \\
\hline TOTAL & & 1.712 \\
\hline
\end{tabular}

Fuente: Elaboración propia, AAAEJ, CLA, Exp. 34, Resumen, p. 8.

De acuerdo a los artículos noveno y onceavo del Reglamento para la dotación se procedió a: "calcular una parcela tipo de 18 hectáreas para cada uno de los 117 individuos capacitados y como estos poseen comunalmente una superficie de $394 \mathrm{Hs}$. la dotación definitiva a la ciudad de Tequila, comprenderá únicamente una superficie de 1,712 Hs. de tierras, la que con todas sus accesiones, usos, costumbres y servidumbres, y con sujeción a la proporcionalidad establecida por el artículo 13 del Reglamento." ${ }^{71}$

Lo que significa, en teoría, que cada uno de los 117 beneficiados con la dotación de tierras recibió 14.63 hectáreas en promedio. Esta expropiación de las tierras se hizo por cuenta del estado federal y los propietarios tuvieron el derecho de reclamar una indemnización por ellas.

El presidente de la república ratificó la decisión del gobernador de Jalisco y declaró definitivamente como legal la dotación de tierras a la comunidad indígena de Tequila el 14 de marzo de 1929. Al respecto el Diario Oficial de la Federación dice textualmente:

"Que terminados los trabajos mencionados en el Resultando anterior y analizadas las constancias existentes en el expediente de que se trata, se verificó que: por Resolución

\footnotetext{
70 AAAEJ, CLA, Exp. 34, Resumen final, p. 8v

71 AAAEJ, CLA, Exp. 34, Resumen final, p. 8v.
} 
Presidencial de fecha 14 de marzo de 1929, publicada en el Diario Oficial de la Federación el 25 de mayo de 1929 y ejecutada el 27 de abril de 1929, se concedió por concepto de dotación de tierras al poblado denominado TEQUILA, Municipio de Tequila, Estado de Jalisco, una superficie de 1,112 Has., para beneficiar a 117 capacitados en materia agraria." ${ }^{72}$

Cuando las tierras fueron expropiadas se aseguró por ley la indemnización a cada uno de los propietarios. El documento es hermético en relación al monto de las indemnizaciones ni cuando se realizaron. Sí asegura que se excluyeron todos los predios menores de 500 hectáreas. A su vez se conmina a los dotados sobre sus obligaciones con las tierras obtenidas, entre ellas destacan: la explotación en común de los terrenos forestales; "mantener, conservar y fomentar la vegetación forestal existente en la superficie de terreno que se les concede;" ${ }^{\prime 33}$ conservar en buen estado los caminos vecinales; el título de propiedad es comunal a fin de amparar y defender la totalidad de la extensión de los terrenos que comprende la dotación.

El acto solemne de entrega de las tierras se hizo efectivo en abril de 1929 (antes de que la ley fuera publicada en el Diario Oficial de la Federación) al Comité Particular Administrativo de la Comunidad Agraria de Tequila con la presencia de todos los capacitados para obtener tierras y, por obvias razones, con la ausencia de los propietarios afectados, quienes fueron debidamente notificados y avisados de la fecha, hora y lugar de la ejecución de la ley.

\section{1a Ampliación de la reforma agraria en Tequila, 1937}

En septiembre de 1935 los ejidatarios solicitaron al gobernador del estado una ampliación del ejido porque las tierras que tenían eran insuficientes para la satisfacción de sus necesidades económicas. En respuesta, la autoridad turnó la solicitud a la Comisión respectiva que procedió a revisar la situación, para ello a mediados de 1936, la Delegación del Departamento Agrario y la Comisión Agraria Mixta pidieron al ingeniero Guillermo J. Palmer que elaborara un informe del estado del ejido de Tequila. En él encontró que 545 hectáreas no se cultivaban porque los terrenos se deslavaron por el declive del terreno y porque tampoco los protegieron, otras tierras antes de agostadero ahora eran de temporal "por renuncia de los mismos ejidatarios a recibir agua, en atención a que según ellos les es incosteable pagar un peso mensual que les cobra el presidente de la Junta de Aguas. ${ }^{\prime 74} \mathrm{El}$ ingeniero además relata que los potreros:

"Las Cárdenas y Santa Cruz están bien cultivados en toda su extensión por sus propietarios; que $20 \mathrm{Hs}$. de temporal que están en los terrenos comunales tampoco los cultivan debido a

\footnotetext{
72 Diario Oficial de la Federación, 25/05/1929. Firma, Emilio Portes Gil.

${ }^{73}$ AAAEJ, CLA, Exp. 34, Resumen final, p. 10.

${ }^{74}$ AAAJ, CLA, Exp 937, 1a Ampliación, p. 2v.
} 
que según les manifestaron los ejidatarios están muy distantes; y que 88 ejidatarios únicamente se encuentran en posesión de tierras." ${ }^{175}$

Como era costumbre se procedió a efectuar un censo que arrojó los siguientes datos: 758 habitantes, 243 jefes de familia varones mayores de 16 años; como también era habitual fue objetado por los propietarios de tierras, pero sin justificar su dicho.

Acorde al informe la Comisión Agraria Mixta determinó que 98 vecinos $^{76}$ tenían derecho a una parcela ejidal, que se detallan en la siguiente tabla:

Tabla 7. 1a ampliación reforma agraria en Tequila, 1937

\begin{tabular}{|c|c|c|c|}
\hline Nombre de las tierras & $\begin{array}{c}\text { Nombre de los } \\
\text { propietarios }\end{array}$ & Superficie afectable & Superficie afectada \\
\hline $\begin{array}{c}\text { San Antonio del } \\
\text { Potrero }\end{array}$ & Francisco García & $\begin{array}{c}634 \mathrm{~h} \text { de agostadero } \\
\text { laborable; } 137.26 \mathrm{~h} \text { de } \\
\text { huerta y árboles frutales y } \\
680.20 \mathrm{~h} \text { de agostadero } \\
\text { cerril }\end{array}$ & $\begin{array}{l}554 \mathrm{~h} \text { de agostadero } \\
\text { con } 50 \% \text { de temporal }\end{array}$ \\
\hline $\begin{array}{l}\text { El Medineño y } \\
\text { Anexas }\end{array}$ & Eladio Sauza $^{77}$ & $\begin{array}{l}4 \mathrm{~h} \text { de riego; } 381 \mathrm{~h} \text { de } \\
\text { temporal, } 1042.10 \mathrm{~h} \text { de } \\
\text { agostadero cerril y monte }\end{array}$ & $\begin{array}{c}4 \mathrm{~h} \text { de riego; } 181 \mathrm{~h} \text { de } \\
\text { temporal y } 1000 \mathrm{~h} \text { de } \\
\text { agostadero cerril y } \\
\text { monte }\end{array}$ \\
\hline El Tigre & Oliva Ruiz & $\begin{array}{l}234 \mathrm{~h} \text { de agostadero cerril } \\
\text { con } 30 \% \text { laborable; } 305 \mathrm{~h} \text { de } \\
\text { agostadero cerril con } 20 \% \\
\text { laborable; } 2000 \mathrm{~h} \text { de } \\
\text { agostadero cerril }\end{array}$ & $\begin{array}{c}234 \text { h de agostadero } \\
\text { con } 30 \% \text { laborable; } \\
262 \text { h de agostadero } \\
\text { cerril. }\end{array}$ \\
\hline San José del Refugio & Aurelio López ${ }^{78}$ & $832 \mathrm{~h}$ de temporal & $241 \mathrm{~h}$ de temporal \\
\hline $\begin{array}{l}\text { El Novillero, Las } \\
\text { Lomas }\end{array}$ & $\begin{array}{l}\text { Guadalupe } \\
\text { Gallardo }\end{array}$ & $\begin{array}{c}357.60 \mathrm{~h} \text { de agostadero con } \\
30 \% \text { laborables }\end{array}$ & $\begin{array}{c}47.20 \mathrm{~h} \text { de agostadero } \\
\text { con } 30 \% \text { laborables }\end{array}$ \\
\hline La Culebra & León Aguirre $^{79}$ & $\begin{array}{c}21 \text { h de agostadero con } 30 \% \\
\text { laborable }\end{array}$ & $\begin{array}{l}21 \mathrm{~h} \text { de agostadero } \\
\text { con } 30 \% \text { laborable }\end{array}$ \\
\hline
\end{tabular}

Fuente: Elaboración propia con base en Expediente 937, Tequila, 1a Ampliación, Archivo de Asuntos Agrarios del estado de Jalisco, pp. 3-5.

\footnotetext{
${ }^{75}$ AAAJ, CLA, Exp 937, 1a Ampliación, p. 3).

${ }^{76}$ Nótese en este expediente ya no se usa el término indígena, sino vecino.

${ }^{77}$ Eladio Sauza "también es propietario de 4 fincas del el estado de Jalisco, con superficie de 7.277h 32cá, 55 á de terrenos de diversas calidades." AAAJ, CLA, Exp. 937, 1a Ampliación, p. 3.

${ }^{78}$ Según el Expediente también es propietario de más de $3.000 \mathrm{~h}$ de terrenos de diversas calidades en Amatitán, Arenal y Zapopan. AAAJ, CLA, Exp. 937, 1a Ampliación, p. 2v.

${ }^{79}$ Según el Expediente también es propietario de varias fincas ubicadas en Tequila, Magdalena y San Cristóbal de la Barranca, AAAJ, CLA, Exp. 937, 1a. Ampliación, p. 3.
} 
Los argumentos de la Comisión Agraria Mixta para afectar las tierras de estos propietarios se sintetizan así: falso fraccionamiento de las tierras; mantenimiento de un administrador general de las mismas, por ejemplo,

"Eladio Sauza es quien por su cuenta y riesgo y en su provecho personal, ejecuta actos de dirección, de explotación y esquilmo, por medio de su administrador General el Sr. Rosalío Guevara, de todas las fracciones en que se dice fue dividida la finca en cuestión, no teniendo ninguna ingerencia (sic) el provecho que obtienen, los demás fraccionistas." ${ }^{80}$

También, mantener a hijos, sobrinos y diversos parientes como fraccionistas; en la práctica la explotación y administración de las fracciones como si nunca se hubiesen dividido, dichos dueños atienden personalmente los predios, ejerciendo actos de dirección, de explotación y de esquilmo.

En síntesis, esta primera ampliación de la reforma agraria en Tequila, repartió una superficie total de $2.544 .20 \mathrm{~h}$, de las que $4 \mathrm{~h}$ eran de riego, $789.66 \mathrm{~h}$ de temporal y $1.750 .54 \mathrm{~h}$ de agostadero cerril, dotando de parcelas a 98 vecinos más una escolar. ${ }^{81}$ Ahora bien los beneficiados debían cumplir una serie de obligaciones entre las cuales enumero las siguientes: conservación de los bosques y los caminos vecinales, cumplir con las disposiciones dictadas por el Departamento Forestal, cooperar con las autoridades municipales y prohibición absoluta de vender 0 arrendar las parcelas. ${ }^{82}$

\section{2a Solicitud de ampliación de reforma agraria y su fracaso, $1980^{83}$}

Parece increíble pero así fue. En marzo de 1980, 154 firmantes con sus respectivas huellas digitales solicitaron al gobierno del Estado dotación de tierras que consideraban susceptibles de afectar, a saber, propiedades de Cuervo S.A. y Sauza S.A. La solicitud presentada por el Comité Ejecutivo Particular y turnada a la Comisión Agraria Mixta, afirma al calce:

\footnotetext{
${ }^{80}$ AAAJ, CLA, Exp. 937, 1a Ampliación, p. 4.

${ }^{81}$ AAAJ, CLA, Exp. 937, 1a Ampliación, p. 5

${ }^{82}$ Agrego para mayor precisión textual: "Inscríbanse esta resolución en el Registro Agrario Nacional y en el de la propiedad, háganse constar las modificaciones que sufren los inmuebles afectados por virtud de esta expropiación publíquese esta resolución en el Diario Oficial de la Federación y en el Periódico Oficial del Gobierno del Estado de Jalisco; notifíquese y ejecútese. Dado en el Palacio de Poder Ejecutivo de la Unión, en México, a los 10/11/1937. Lázaro Cárdenas.-Rúbrica.-PRESIDENTE CONSTITUCIONAL DE LOS ESTADOS UNIDOS MEXICANOS.-GABINO VÁZQUEZ.-RÚBRICA.-Jefe del Depto. Agrario. Es copia debidamente cotejada con su original, SUFRAGIO EFECTIVO NO REELECCIÓN. México D. F. 15/12/1937. P. A. del Secretario General el Oficial Mayor. Salvador Teuffer. Sentada para su inscripción hoy a las 12 horas, registrada bajo la inscripción número 68 en las páginas de la 109 a la 114 del libro 46 de la sección primera, quedando señalada la finca con el número de orden 139 que les corresponde Tequila, Jal. a 01/12/1943." AAAJ, Expediente 937, 1ạ Ampliación, p. 6.

${ }^{83}$ Esta sección del trabajo está construido con base en la documentación del AAAEJ, CLA, Exp. 4026, 2ª Ampliación, 1980.
} 
"Los suscritos, mexicanos, mayores de edad, peones ${ }^{84}$, con domicilio conocido en la población de Tequila, Jal. Exponemos: que en virtud de que hemos venido trabajando terrenos propiedad de las haciendas pertenecientes a las casa denominadas Cuervo, S.A. y Sauza, S.A. desde que hemos tenido uso de razón y que hasta la fecha no poseemos propiedad rural ni urbana y que el único medio de manutención de los que suscribimos y de nuestras familias es el salario que devengamos como peones de las citadas haciendas, nos vemos en la necesidad de recurrir ante Ud., solicitando se inicie procedimiento de dotación de tierras a los suscritos, en vía de Segunda Ampliación del ejido definitivo denominado TEQUILA [...] a fin de estar a (sic) posibilidad de satisfacer nuestras necesidades económicas, dado que el salario que devengamos como peones de las haciendas de propiedad de las empresas industriales [...] no es suficiente para satisfacer nuestras necesidades más imperiosas y además porque estimamos que nuestras convicciones económicas sociales satisface los extremos de los Artículos 195, 196, 197, 200 y 202 de la Ley Federal de Reforma Agraria." 85

Dicha solicitud apareció publicada en el Diario Oficial del estado de Jalisco en agosto de 1980, pasaron varios años de dimes y diretes hasta que, otra vez, por resolución presidencial publicada en el mismo periódico en 7 de agosto de 1985 se les concedieron:

"por concepto de segunda ampliación [...] una superficie de 73 hectáreas de agostadero con $50 \%$ susceptible de cultivo, que se tomarían íntegramente de la fracción El Ocote, que forma parte del predio El Medineño, propiedad de Francisco Javier Sauza Mora [uno de los nietos más avispados de Cenobio Sauza Madrigal], para beneficiar a 75 campesinos capacitados, [sin embargo], no obran constancias en auto de que se haya ejecutado." ${ }^{86}$

Fue suficiente y bastó para levantar ámpulas entre los propietarios susceptibles de expropiar. Eran otros tiempos. La mayor parte estaba organizada en la Federación de la Pequeña Propiedad de Jalisco que en voz de su presidente José Rosas Gómez Luna, comenzaron a defenderse de un posible reparto. Se hicieron valer abogados y representantes legales, también copias heliográficas certificadas y simples, planos topográficos, escrituras notariales para probar y demostrar la propiedad legal de sus tierras, pero lo más importante, acreditar que no eran objeto de reparto pues sus predios estaban protegidos por la declaratoria de inafectabilidad emitida por el presidente de la república en marzo de $1937^{87}$ pero no fue esta

\footnotetext{
${ }^{84}$ Aún en 1980 se autonombran peones y no campesinos.

${ }^{85}$ AAAEJ, CLA, Expediente 4026, Primer apartado, p.

${ }^{86}$ AAAEJ, CLA, Exp. 4026, $2^{\circ}$ apartado, p. 2

${ }^{87}$ Agrego lo que afirma Gómez de Silva Cano, J., 2017 en, "Evolución del marco jurídico agrario", en El derecho agrario mexicano y la Constitución de 1917, INEHRM, https://archivos.juridicas.unam.mx/www/bjv/libros/9/4452/16.pdf. “Mediante decreto del 1 de marzo de 1937, expedido por el presidente Lázaro Cárdenas y publicado el 6 del mismo
} 
la única ley bajo la que se ampararon, ${ }^{88}$ también se hicieron valer de la Procuraduría Agraria y los Tribunales Agrarios que permitieron la defensa de la pequeña propiedad.

Lo que dio al traste con la solicitud de dotación de tierras de los jornaleros de Tequila bien pudo ser la aprobación de la reforma al Artículo 27 de la Constitución, en febrero de 1992, bajo el gobierno de Carlos Salinas de Gortari, porque los tribunales admitieron el amparo a Eladio Sauza Gutiérrez que era el principal afectado y, en 1993, las instancias legales negaron definitivamente la dotación de tierras solicitada en el documento Segunda Ampliación. Este, además, logró convencer que las propiedades mencionadas como susceptibles de afectabilidad por los peones, las había comprado por partes, en distintas fechas, estaban todos plantadas de agaves, no formaban una unidad, sino estaban fraccionadas, situación a todas luces simulada porque, si se suman todas las hectáreas de tierras bajo su propiedad superaban con creces los límites establecidos por el Código Agrario de 1940 de 200 hectáreas.

En relación al uso de los conceptos habría que remarcar que, en esta solicitud de segunda petición de ampliación del ejido de Tequila, sigue estando ausente la noción de campesino, es claro que en esta los solicitantes se nombran a sí mismos peones que trabajan en las haciendas. Al respecto la misma ley cardenista de 1937 lo especifica pues incorpora como sujetos agrarios a los peones y trabajadores de las haciendas y se promueve la organización de los ejidatarios para la explotación de los recursos, por lo tanto, estos pudieron como tales hacer su solicitud de dotación de tierras.

Finalmente, es de gran utilidad para el lector la cartografía con el resultado de la reforma agraria ejecutada por las instancias legales de Jalisco en Tequila, por ello, proporciono al final del texto el mapa de la división ejidal de la década de 1930, realizada con base en representaciones cartográficas heliográficas originales.

\footnotetext{
mes y año, se adiciona el Código Agrario con el fin de impulsar el desarrollo pecuario a través del otorgamiento de concesiones de inafectabilidad ganadera a grupos de particulares, por un término de 25 años, amparando superficies que no excedieran de 300 hectáreas de buena calidad y hasta 50 mil [...] para las desérticas." Más adelante este mismo autor señala que el nuevo Código Agrario de 1940 promulgado por Lázaro Cárdenas es más específico aún pues "señala como límite de la pequeña propiedad la superficie de no excediera 100 hectáreas de terrenos de riego o humedad, 200 hectáreas de terrenos de temporal o de agostadero susceptibles de cultivo, 150 hectáreas de terrenos dedicados al cultivo de algodón o henequén y 300 hectáreas de terrenos dedicados a las plantaciones de cacao y árboles frutales." Pp. 183 y 186 respectivamente.

${ }^{88}$ Entre 1937 y 1992, entre ellas destaca el nuevo Código Agrario de 1942, la de diciembre de 1946, luego siguen la promulgación de varios decretos leyes: 1948, 1949, 1959, 1962; la Ley Federal de Reforma Agraria de 1971 que reemplazó al anterior código, más adelante le siguieron los decretos leyes de 1972, cuatro más en 1974, otros adicionales en 1976, 1980, 1983, Gómez de Silva Cano, J., 2017, “Evolución del marco..., pp. 184-200.
} 

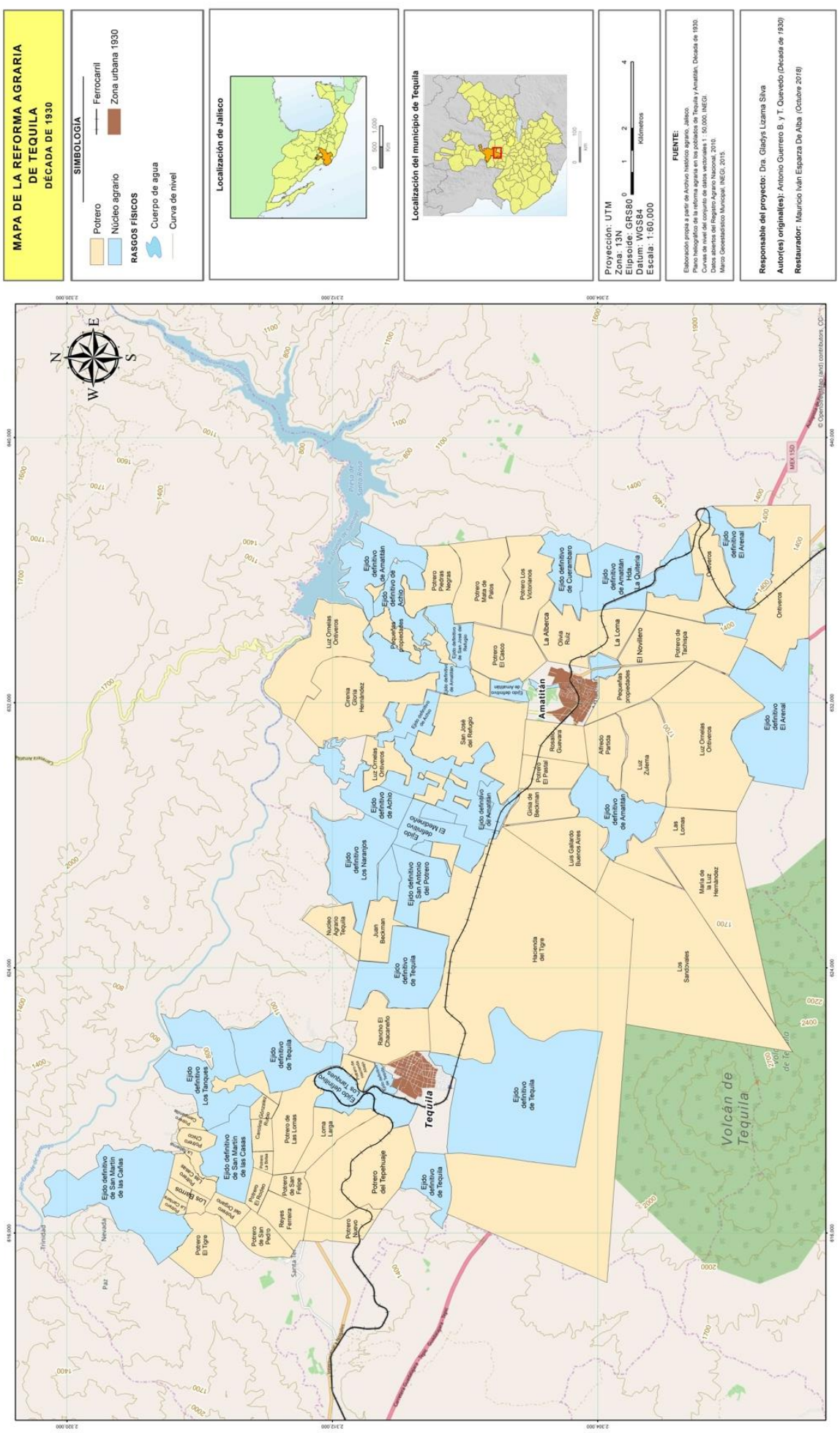


\section{Conclusiones}

La primera conclusión a resaltar es conceptual. Tanto la historiografía jalisciense como la documentación revisada sobre la reforma agraria en Tequila son definitorias en relación a la ausencia del concepto campesino. En las fuentes documentales consultadas y revisadas los sujetos susceptibles de recibir tierras se nombraban indígenas, peones o vecinos nunca campesinos.

Según la documentación revisada y uno de los autores que ha estudiado la producción de tequila, Rogelio Luna Zamora, el impacto de la reforma agraria fue negativo en relación a la producción de agave pues se redujo considerablemente el porcentaje de hectáreas cultivadas y número de plantas entre 1930 y 1940 . Para ser fiel a sus datos, en 1930 había $7.498 \mathrm{~h}$ cultivadas con 9.885.081 plantas de agave y en 1940 se había reducido a 2.603 h con 4.007 .615 de unidades, lo que significó una disminución de $75 \%$ de la superficie dedicada al cultivo de agave y $59 \%$ menos de plantas. Los principales afectados fueron los propietarios de las plantaciones y "los industriales, destiladores y envasadores de tequila." ${ }^{89}$

Si bien es cierto la reforma agraria en Tequila sí profundizó la crisis de la producción de maguey y tequila -que tiene sus orígenes en la primera década de 1900, de la cual no se recuperó hasta la de los 50 en adelante-, habría que matizar esta conclusión pues, según los mismos datos, el porcentaje de las tierras afectadas por la Reforma Agraria, entre 1930 y 1941, solo fue de un $20 \%$ del total de las hectáreas en propiedad privada y si agregamos que fueron tierras de agostadero y de temporal, entonces es dudable que la producción de agave se deteriorara tanto, porque los hacendados agaveros bien pudieron continuar su producción en las tierras que mantuvieron bajo su control que eran infinitamente mayores que las ejidales. 0 sea, habría que indagar más en los factores que indican una disminución de la producción tanto de agave como de tequila y no quedarse solo con esta respuesta como causa principal del desastre del reparto agrario.

Pienso que uno de los rasgos necesarios de tomar en consideración es el impacto que la guerra cristera (1927-1929) provocó en la crisis de la producción agrícola, sobre todo, de los básicos para la alimentación de la población y también en la producción agavera y posterior de tequila; según Jean Meyer, con base en datos de la Dirección General de Estadística de México, sostiene que en 1929 se registró una disminución de $25 \%$ en la producción de maíz respecto a la cifra de 1925 , una baja de $50 \%$ en la de frijol en los mismos años. Este descenso se produjo en gran medida debido a la disminución de la superficie sembrada en el espacio en conflicto de Jalisco y otras regiones en guerra. ${ }^{90}$

\footnotetext{
89 Luna Zamora, R. 1999, La historia del tequila..., pp. 101-103.

${ }^{90}$ Meyer, Jean, 1995, La cristiada..., Vol. III, p. 267.
} 
Esta crisis alimentaria, de miseria creciente fue la causante de otro proceso que estuvo directamente relacionado con el deterioro de la producción de mezcal y tequila: la emigración de la población hacia Estados Unidos o hacia las ciudades cercanas, provocando que hubiera una menor cantidad de fuerza de trabajo disponible para el cultivo y fabricación de los productos mencionados. Cito a Meyer: "De 1925 a 1929 entraron a Estados Unidos 250.000 mexicanos (el 16\% de todos los inmigrantes), empujados por la guerra y la crisis económica, [...] miseria y huida del pueblo, ruina y quiebra de los grandes agricultores." ${ }^{\prime 1}$

Como se constata en el relato de Jean Meyer, es claro que la guerra cristera profundizó la grave crisis económica que asoló las haciendas desde años antes de la misma en el Bajío y en el oeste de México; muchos abandonaron las fincas, muchos no tuvieron ninguna chance de sembrar y, los que sí, corrieron riesgos para llevar al mercado lo que obtenían de sus tierras. En suma, pudo observarse una casi paralización de actividades que arruinaron a los productores agrícolas y sellaron la descomposición de lo que fue la gran propiedad, situación de la cual nunca se recuperó.

A lo anterior hay que añadir la crisis que asoló al país después de 1929, situación que golpeó nuevamente la producción de agave y de tequila.

Una medida que nada tiene que ver con la reforma agraria pero que sí afectó para mal la producción de tequila, fue la promulgación de la ley seca que prohibió la producción y el consumo de bebidas de alta graduación de alcohol en 1920, en varios Estados de la república. El objetivo era evitar la embriaguez en los sectores populares.

También pudo tener un peso en el descenso de la producción de tequila en esos años lo aseverado por Rogelio Luna en su segundo libro, a saber: baja en la demanda por la competencia que desató la preferencia de los consumidores por el brandy, whisky, ron y cerveza. ${ }^{92}$

La inestabilidad política de la época es un factor a tener en consideración en el retraso de la puesta en práctica de la Reforma Agraria. Entre 1915 y 1929 hubo una larguísima lista de gobernadores de Jalisco que evidencia lo afirmado en líneas anteriores; ¿quiénes se incluyen es este listado por orden cronológico?: Manuel M. Diéguez, Manuel Aguirre Berlanga, Julián C. Medina, Emiliano Degollado, Manuel Bouquet, Luis Castellanos y Tapia, Ignacio Ramos Praslow, Francisco Labastida Izquierdo, Basilio Vadillo, Antonio Valadez Ramírez, José Guadalupe Zuno (en dos ocasiones separadas entre sí), Francisco Tolentino, Aurelio Sepúlveda, Clemente Sepúlveda, Silvano Barba González, Daniel Benítez, Margarito Ramírez, José María Cuellar. Para enfatizar, entre 1914 y 1926 hubo 14 gobernadores en el Estado.

\footnotetext{
${ }^{91}$ Ibid, pp. 269-270.

92 Luna Zamora, R. 2015, La Construcción cultural.., pp. 116-117.
} 
Desde el punto de vista legal hubo un perfil modelo de cómo debía llevarse a cabo el proceso de reparto agrario, sin embargo, la comunidad de Tequila debió enfrentar un sinnúmero de problemas como la búsqueda de documentación que avalara su solicitud, la renuencia de los propietarios a ser afectados y la connivencia de algunas autoridades locales y los conflictos internos para no hacerlo.

El proceso de afectabilidad de las tierras de los propietarios no fue lineal ni mucho menos terso, se tardó años, por lo menos catorce en el caso de Tequila en la primera etapa. Por la historiografía regional se sabe que estuvo lleno de sinuosidades, tiras y aflojas y conflictos entre propietarios y ejidatarios y entre los ejidatarios mismos. Los terratenientes se oponían a ser expropiados, los beneficiarios probables del reparto utilizaron con frecuencia la violencia física para hacer cumplir las disposiciones de la Comisión Local Agraria, los presidentes municipales y autoridades agrarias no eran respetadas por los propietarios y a veces rebasadas por los solicitantes de tierras. Los militares y sus armas fueron utilizados en muchas ocasiones contra los ejidos y sus habitantes ya fuera para apoyar a los propietarios o en beneficio propio. Las formas de resolución de las pugnas fueron tanto a través de las vías legales, pero también y con mucha frecuencia con violencia física, robo, asesinato e invasión de tierras.

Por último, con la aplicación de la reforma agraria el ejido se llena de un nuevo significado legal y simbólico, de ser solo la propiedad comunal de los pueblos indígenas, pasó a constituirse en una institución jurídica colectiva con capacidad legal, patrimonio propio y órganos representativos.

\section{Archivos}

Archivo de Asuntos Agrarios de Jalisco Comisión Local Agraria:

- Expediente $\mathrm{N}^{\circ} 34$,

- Expediente 1a Ampliación 1937, № 937,

- Expediente 2a Ampliación 1980, № 4026

- Plano Heliográfico de la Reforma Agraria en los poblados de Tequila y Amatitán, 1930.

\section{Bibliografía}

Barreto, C. 2019. "La persistencia de los hacendados azucareros del estado de Morelos frente al reparto agrario, 1920-1930. Un estudio de caso", en Letras Históricas № 20, Universidad de Guadalajara, pp. 91-113. http://www.letrashistoricas.cucsh.udg.mx/index.php/LH/article/view/7148/6415

Baitenmann, H. 2017, "Ejerciendo la justicia fuera de los tribunales: de las reivindicaciones decimonónicas a las restituciones de la reforma agraria", en Historia Mexicana, LXVI, 4, Mexico, pp. 2013-2072.

Falcón, R. 1978. "El surgimiento del agrarismo cardenista: una revisión de las tesis populistas", Historia Mexicana, Vol. 27, N³, Mexico, pp. 333-386.

Gómez, L. 2009. "Ser indígena en la reforma agraria. Jalisco, México, 1915-1924", revista Sociedad Hoy N 17, Universidad de Concepción, Chile, pp. 103-113. 
Gómez, L. 2009. Identidades locales y la conformación del estado mexicano, 1915-1924: comunidades, indígenas y pobres ante el reparto agrario en Jalisco central, Guadalajara, Universidad de Guadalajara, Tesis de doctorado.

Gómez, J. 2017. “Evolución del marco jurídico agrario”, en Gómez de Silva Cano, J. El derecho agrario mexicano y la Constitución de 1917, Mexico, INEHRM.

Jarquín, M. T. 1990. Origen y evolución de la hacienda en México: siglos XVI al XX, Mexico, El Colegio Mexiquense A.C., Universidad Iberoamericana, Instituto Nacional de Antropologia e Historia

Knowlton, R. 1978, "La individualización de la propiedad corporativa civil en el siglo XIX - Notas sobre Jalisco", en Historia Mexicana, Vol. 28, N 1 (109), Mexico, pp. 24-61.

Kourí, E. 2017. "Sobre la propiedad comunal de los pueblos. De la Reforma a la Revolución", Historia Mexicana, LXVI, 4, Mexico, pp. 1923-1960.

Lillo, B. 1904. Sub terra, Santiago de Chile, Imprenta Moderna.

Luna, R. 1999. La historia del tequila, de sus regiones y sus hombres, México, CONACULTA.

Luna, R. 2015. La Construcción cultural y económica del tequila, Guadalajara, Universidad de Guadalajara.

Martínez, H. y Quiñones, M. 2013. "La cartografía de la reforma agraria en la época temprana: Jalisco, 1918-1922", en García, I. (Coord.). Historia locales en tiempos globales, Guadalajara, Universidad de Guadalajara/Plaza y Valdés Editores, pp.137-174.

Márquez, G. 2007. “¿Modernización fiscal? Impuestos sobre bebidas alcohólicas, 1884-1930”, en Sánchez, E. (Coord.). Cruda realidad. Producción, consumo y fiscalidad de las bebidas alcohólicas en México y América Latina, siglo XVII-XX, México, Instituto Mora, pp. 186-212.

Meyer, J. 1995. La Cristiada. Los cristeros, Vol III, México, Siglo XXI.

Molina, A., Varias ediciones desde 1909, Los grandes problemas nacionales y La propiedad agraria en México.

Navarro, A. y Goyas, R. 2013. "La tierra de los pueblos en la región Valles de Jalisco, de la Independencia a la Revolución Mexicana", en Estudios Agrarios, revista de la Procuraduría Agraria, Mexico, pp. 177197.

Navarro, A. y Goyas, R. 2015, “Desintegración de la hacienda y conformación de ejidos en el valle de Ameca, Jalisco. El caso de la hacienda El Cabezón”, revista Secuencia N 92, Mexico, pp. 139-166.

Warman, A., s/f, "La reforma agraria mexicana: una visión de largo plazo". Consultado el 21/10/2019 http://www.fao.org/3/i0415t/i0415t09.htm 